\title{
Fibre Optic Methods of Prospecting: A Comprehensive and Modern Branch of Geophysics
}

\author{
Mulugeta C. Fenta $^{1,2}$ (D) David K. Potter ${ }^{3}$ (D) . János Szanyi ${ }^{1}$
}

Received: 21 December 2019 / Accepted: 5 February 2021 / Published online: 9 March 2021

(c) The Author(s) 2021

\begin{abstract}
Over the past decades, the development of fibre optic cables, which pass light waves carrying data guided by total internal reflection, has led to advances in high-speed and long-distance communication, large data transmission, optical imaging, and sensing applications. Thus far, fibre optic sensors (FOSs) have primarily been employed in engineering, biomedicine, and basic sciences, with few reports of their usage in geophysics as point and distributed sensors. This work aimed at reviewing the studies on the use of FOSs in geophysical applications with their fundamental principles and technological improvements. FOSs based on Rayleigh, Brillouin, and Raman scatterings and fibre Bragg grating sensors are reviewed based on their sensing performance comprising sensing range, spatial resolution, and measurement parameters. The recent progress in applying distributed FOSs to detect acoustic, temperature, pressure, and strain changes, as either single or multiple parameters simultaneously on surface and borehole survey environments with their cable deployment techniques, has been systematically reviewed. Despite the development of fibre optic sensor technology and corresponding experimental reports of applications in geophysics, there have not been attempts to summarise and synthesise fibre optic methods for prospecting as a comprehensive and modern branch of geophysics. Therefore, this paper outlines the fibre optic prospecting methods, with an emphasis on their advantages, as a guide for the geophysical community. The potential of the new outlined fibre optic prospecting methods to revolutionise conventional geophysical approaches is discussed. Finally, the future challenges and limitations of the new prospecting methods for geophysical applications are elucidated.
\end{abstract}

Keywords Fibre optic methods · Distributed fibre optic sensors · Prospecting · Geophysics

\section{Abbreviations}

ADTS

$\mathrm{Al}$

Mulugeta C. Fenta

fentamulugeta@gmail.com

1 Department of Mineralogy, Geochemistry, and Petrology, University of Szeged, Egyetem u 2, 6722 Szeged, Hungary

2 School of Earth Science, Bahir Dar University, P.O. Box 69, Bahir Dar, Ethiopia

3 Department of Physics, University of Alberta, Edmonton, AB T6G 2E1, Canada 


$\begin{array}{ll}\text { BOTDA } & \text { Brillouin scattering-based optical time-domain analysis } \\ \text { BOTDR } & \text { Brillouin scattering-based optical time-domain } \\ & \text { reflectometry } \\ \text { CW } & \text { Continuous wave } \\ \text { DAS } & \text { Distributed acoustics sensors } \\ \text { DAS VSP } & \text { Distributed acoustic sensing vertical seismic profiling } \\ \text { DATS } & \text { Distributed acoustic and temperature sensor } \\ \text { DFOGS } & \text { Distributed fibre optic geophysical sensor } \\ \text { DFOS } & \text { Distributed fibre optic sensor } \\ \text { DPS } & \text { Distributed pressure sensor } \\ \text { DSS } & \text { Distributed strain sensor } \\ \text { DTS } & \text { Distributed temperature sensor } \\ \text { DWDM } & \text { Dense wavelength division multiplexing } \\ \text { FBG } & \text { Fibre Bragg grating } \\ \text { FEM } & \text { Finite element method } \\ \text { FOS } & \text { Fibre optic sensor } \\ \text { HD } & \text { High definition } \\ \text { HWC } & \text { Helically wrapped cable } \\ \text { LED } & \text { Light-emitting diode } \\ \text { OTDR } & \text { Optical time-domain reflectometry } \\ \text { PCF } & \text { Photonic crystal fibre } \\ \text { PSC } & \text { Pure silica glass composition } \\ \text { Raman-based OTDR } & \text { Raman back-scattering-based optical time-domain } \\ & \text { reflectometry } \\ \text { Rayleigh-based OFDR } & \text { Rayleigh back-scattering-based optical frequency-domain } \\ \text { Rayleigh-based phase OTDR } & \text { reflectometry } \\ \text { Sayleigh back-scattering-based phase optical time-domain } \\ \text { SPR } & \text { reflectometry } \\ \text { SSP } & \text { Signal-to-noise ratio } \\ \text { TDM } & \text { Surface plasmon resonance } \\ \text { VCSEL } & \text { Surface seismic profiling } \\ \text { VSP } & \text { Time division multiplexing } \\ \text { WDM } & \text { Vertical-cavity surface-emitting laser } \\ & \text { Vertical seismic profiling } \\ \text { Wavelength division multiplexing } \\ \end{array}$

\section{Article Highlights}

- Fibre optics sensor technology is rapidly growing using the fibre cable as a sensor, but the potential for utilising this technology in geophysics has mostly been unexploited.

- Optical cables and sensor technology enable high sensitivity sensing, high spatial resolution, fast recording time, high data acquisition, and transmission at the speed of light, which can give rise to new types of interpretation methodologies.

- Fibre optic sensor technology allows the geophysical community to detect several physical properties of earth materials (acoustics, temperature, pressure, strain, and others) with dense data sampling. 
- Fibre optic sensor technology presents a comprehensive set of modern geophysical methods that can be integrated with the world's latest technology standard in data transmission.

\section{Introduction}

Modern geophysical techniques rely on large amounts of data and high sensitivity sensors to identify the measurand from the noise. Some conventional geophysical methods can be difficult and expensive to conduct. To gather geophysical data more efficiently and gain a competitive advantage, fibre optic cables and sensors are a promising possibility. Fibre optic cables, comprised of glass or plastic and used for data transmission and parameters sensing, are flexible and can possess single or multiple assemblages (Chabay 1982). Optical fibres are used mainly in communication due to the rapid data transmission enabled by optical signals over long distances compared to electrical signals transmitted through conventional wirelines. Copper wires, first used as a waveguide and signal transmitter for telecommunication purposes during the nineteenth century, were expensive and limited to a certain range of frequencies, leading scientists to search for new waveguide techniques.

The search to develop an alternative waveguide system for data transmission, focusing on reducing the weight, implementation cost, and increasing the operational bandwidth, became prominent due to the invention of fibre optics by Narinder Singh Kapany in 1955 at the University of London. Kapany's design had the capacity to transmit an image over a distance of $1 \mathrm{~m}$ by using light as a carrier (Rastogi 2018). The invention of the laser as a source of light in the 1950s (Alwis et al. 2016), followed by improvements to the optical fibre waveguide by Charles Kao and George Hockam in 1966, reduced the signal loss in the fibre from 1000 to $20 \mathrm{~dB} / \mathrm{km}$. Keck Donald (Hecht 1999) achieved an attenuation of $20 \mathrm{~dB} /$ $\mathrm{km}$ in 1970. In the same year, Corning Glass Works produced a fibre with a $16 \mathrm{~dB} / \mathrm{km}$ signal loss at a wavelength of $633 \mathrm{~nm}$, and within a few decades, the signal loss was reduced to less than $0.2 \mathrm{~dB} / \mathrm{km}$ (Rastogi 2018). After its invention, fibre optics cable communication passed through several stages, including laser sources, enhanced transmission rate capacity, increased transmission distances, a broadened bandwidth, and fifth-generation dense wavelength division multiplexing (DWDM). These enabled one to increase information rates further, and in 1995, data transmission over a distance exceeding $11,300 \mathrm{~km}$ at an information rate of $5 \mathrm{Gbit} / \mathrm{s}$ with repeaters of $60 \mathrm{~km}$ was demonstrated utilising submarine links (Otani et al. 1995). Nowadays, many telecom companies widely use fibre optics for signal transmission, since it is a reliable technology proven in large-scale networks and state-of-the-art communications.

Besides their proven characteristics of data transmission capacity, fibre optic cables' ability to detect single or several parameters at a point or along their entire length attracted scientists' attention in different disciplines. Fibre optic point sensors were first applied in biomedicine (Tosi et al. 2018), chemistry (Castrellon-Uribe 2012), and engineering (Fidanboylu and Efendioglu 2009). In geophysics, fibre optic technology has been applied in the oil and gas industry over the last 20 years, initially focusing on downhole, single-point temperature and pressure sensing in 1993 (Silkina 2014). Later, it was used as distributed temperature and acoustic sensors resulting from developments in the telecom industry (Lu et al. 2019a). Using distributed fibre optic sensors in geophysical applications is a unique opportunity for the geophysical community. 
Fibre optic sensors have several applications for passively detecting the physical properties of earth materials. These sensors can sense physical properties, including pressure, temperature, vibration, strain, physical displacement, light intensity, rotation, magnetic field, electric field, radiation level, fluid flow, and liquid level (Lu et al. 2019a). Despite the vast potential, only a few of them (pressure, temperature, vibrations, and strain) have been field-tested and well demonstrated during the last couple of decades (Lu et al. 2019a) and thus considered as standard capabilities. The field experiments have mainly taken place in the oil and gas industry with minimal educational institutions' works. Field tests are comprised of point pressure sensors, distributed acoustics sensors (DAS), distributed temperature sensors (DTS), distributed pressure sensors (DPS), and distributed strain sensors (DSS). The DAS, DTS, DPS, and DSS detection technologies are based on Brillouin, Raman, and Rayleigh back-scattering of light and fibre Bragg grating (FBG) techniques. These distributed sensors have been applied in mining, geothermal studies, earthquake detection, landslide detection and prediction, hydraulic fracturing, and tunnel construction (Ajo-franklin et al. 2019; Bakku et al. 2014a, b; Karrenbach et al. 2019; Li and Zhan 2018; Nesladek 2017; Paulsson et al. 2019).

Field experiments using fibre optic sensing technology for geophysical applications are increasing, and their results have been presented at several conferences. The technology has been applied as distributed single-parameter detectors and multi-parameter hybrid sensors for near-surface and borehole geophysical surveys. Its capability to integrate more than two fibre optic sensors to detect two or more physical parameters simultaneously (Karrenbach et al. 2019; Muanenda et al. 2016; Zhang et al. 2016) is a tremendous advantage of the technology. Fibre optic sensors offer various unique benefits, including high response rates, low fabrication costs, lightweight, high sensitivity, and non-reactivity to electromagnetic interference (Sidek and Afzal 2011). Moreover, the fibre optics cable capacity with low signal attenuation, low signal absorption, high bandwidth, and high bit transmission renders these sensors ideal for geophysical applications. However, it has not been well exploited in geophysics and further developments are desirable. Thus far, the geophysical community has not taken advantage of these modern sensing techniques. There is little in terms of review literature showing that fibre optic technology is an essential, modern, and comprehensive branch of geophysics.

Despite these advantages to the geophysical community, there are also limitations that need to be solved in the future. Improvements in fibre optics sensing technologies are required, including sensing range, spatial resolution, and measurement sensitivity for fieldtested techniques. Further works are necessary to change laboratory-scale experiments into field measuring geophysical applications. Progress is required to apply recent data transmission power and computational skills such as deep learning, machine learning, and artificial intelligence to the new sensing techniques. Therefore, this review's principal aim is to present fibre optical science basics, sensor technology, and its applications in geophysics from comprehensive open-source information. The paper aims to present the progress and practices of distributed fibre sensing technology and multi-parameter simultaneous measurement techniques based on back-scattering of light and FBG while applied to near-surface and borehole geophysical surveys. Moreover, this review presents fibre optic sensing technology as a comprehensive, modern tool for geophysical prospecting. The paper also aims to outline the limitations of fibre optics sensing technology in geophysics and suggest future focus areas to improve the new techniques. 


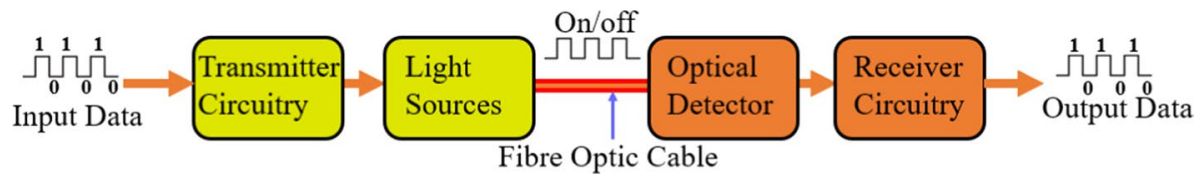

Fig. 1 Simple optical fibre data transmission framework. Modified from Elprocus (2019)

(a)

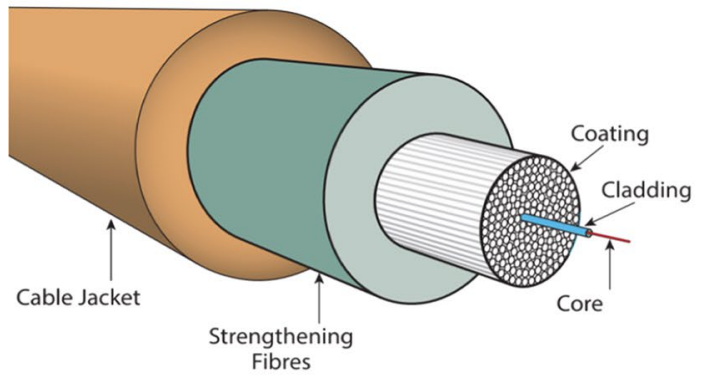

(b)

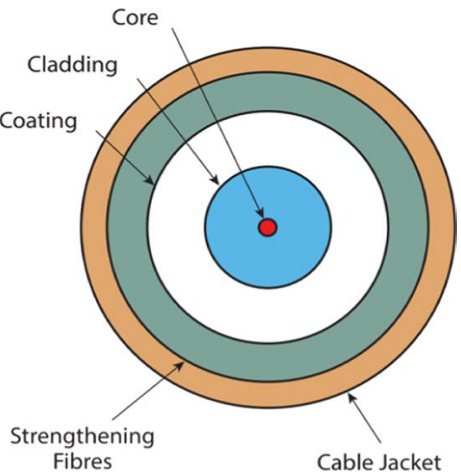

Fig. 2 Basic structure of an optical fibre (a) as modified from Fidanboylu and Efendioglu (2009), and the internal structure of an optical fibre (b) modified from Media (2019)

\subsection{Basics of data transmission with fibre optics}

A fibre optic data transmission system has four primary components: an optical source/ transmitter, an optical fibre cable, connectors, and an optical sensor/receiver (Fig. 1). Combining these components enables data transmission over distances on the order of miles in light pulses through the optical fibre. The transmitter, which converts the electrical signal to an optical signal, contains a light source, such as a light-emitting diode (LED), fibre diode, laser diode, or a vertical-cavity surface-emitting laser (VCSEL). Lasers have the smallest spectral width and the greatest bandwidth, while LEDs have the largest spectral width with lower bandwidth. The emission of ultraviolet, visible, or infrared radiation by the fibre at specific wavelengths depends on the construction material of choice (Skoog et al. 2007). Fibre optic sources mostly generate light in the infrared band, specifically at 850,1300 , and $1550 \mathrm{~nm}$.

A fibre optic cable used as a data transmission medium consists of a bundle of thin optic fibres. When the modulated light propagates through the fibre, its signal will be enhanced by optical amplifiers and received by a photodetector that converts light to an electrical signal. A single thin optic fibre consists of three primary components: the core, the cladding, and the coating or buffer (Fig. 2). The very thin core in the centre of the fibre, with a small diameter varying from 8 to $63 \mu \mathrm{m}$, is a cylindrical rod of dielectric material. The cladding that surrounds the core is a dielectric component with a lower refractive index than that of the core. Light propagates primarily along the fibre core, where the core-cladding arrangement creates an optical waveguide that confines the light in the core by total internal reflection at the core-cladding interface. The light traveling through the optical fibre carries information in the same manner as an electrical transmission copper conductor, and data transmission occurs at 99.7\% of the speed of light in a vacuum (Rajpoot et al. 2017). 
The coating or buffer encloses the cladding to protect the optical fibre from physical damage, preventing abrasions due to its elastic nature, and preventing scattering losses caused by microscopic bends (Jones 1998).

Light travels along the multi-mode fibre optic cable via total internal reflection. Internal back reflection of light inside the multi-mode fibre core occurs first at the critical angle of incidence, as determined by Snell's law (Mahajan 2014). At any angle of incidence greater than the critical angle, light is reflected into the fibre glass medium (Fig. 3a). Light travels down the fibre optic cable by repeatedly reflecting off the walls, with the fibre acting as an electromagnetic surface waveguide (Jones 1998). The optical fibres are classified as single-mode or multi-mode fibres based on the core diameter, and as step-index and gradient-index fibres based on the refractive index profile. The mono-mode fibres have a narrow glass core, most commonly with a core diameter of $8-10 \mu \mathrm{m}$, with a uniform refractive index profile and are known as step-index fibres. They transmit only a single mode of light within a specific wavelength range for a linearly polarised state. Multi-mode fibres have a large diametric core, with a core-cladding diameter ratio of 50/125 or 62.5/125 $\mu \mathrm{m}$, allowing multiple modes of light to propagate, and can be either step index or gradient index (Fig. 3b). The multi-mode gradient-index fibres have a nonlinear, rotationally symmetric index profile, with the index decreasing from the centre of the fibre outwards (Jenny 2000). This refractive index arrangement causes the light to travel at a constant speed until it reaches the receiver. However, the multi-mode fibres exhibit high dispersion and attenuation rates, which degrade the signal quality and limit its long-distance application. In contrast, the single-mode fibres have a lower attenuation and greater signal length, making them ideal for long-distance applications.

\section{Fibre Optic Sensors}

The capacity of a fibre to be used as a sensor is its most useful characteristic. When a fibre is used as a sensor, a light beam is converted into an electrical signal, and the sensor measures the physical parameters of the light and translates the information into an output read by an instrument. Numerous optical fibre structures, including single-mode fibres, multi-mode fibres, photonic crystal fibres (PCFs), fibre gratings, and surface plasmon resonance (SPR) structures, are used to produce sensors for different applications (Alwis et al. 2016). The fibre optic sensor presented by Momota and Hasan (2018) has a simple hollow-core circular lattice PCF and is based on SPR, which was designed using a finite element method (FEM). An optical fibre sensor's photosensitivity is the most valuable

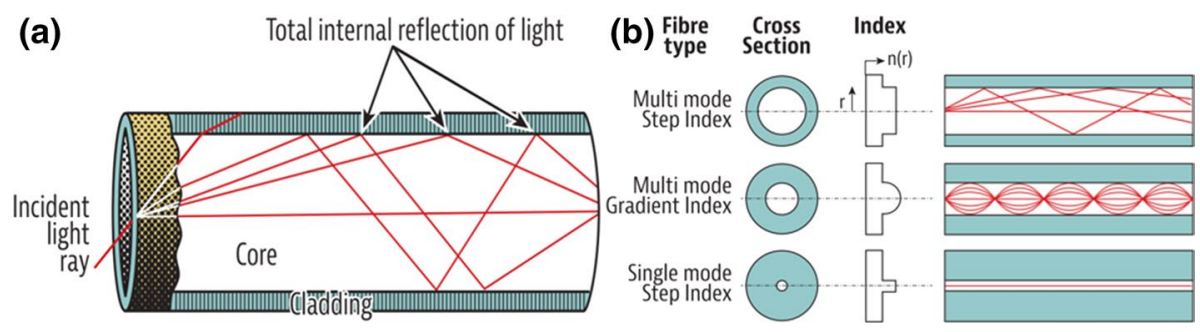

Fig. 3 Total internal reflection in a multi-mode optical fibre (a) as modified from Media (2019), and different mode types of optical fibres (b) modified from Jenny (2000) 


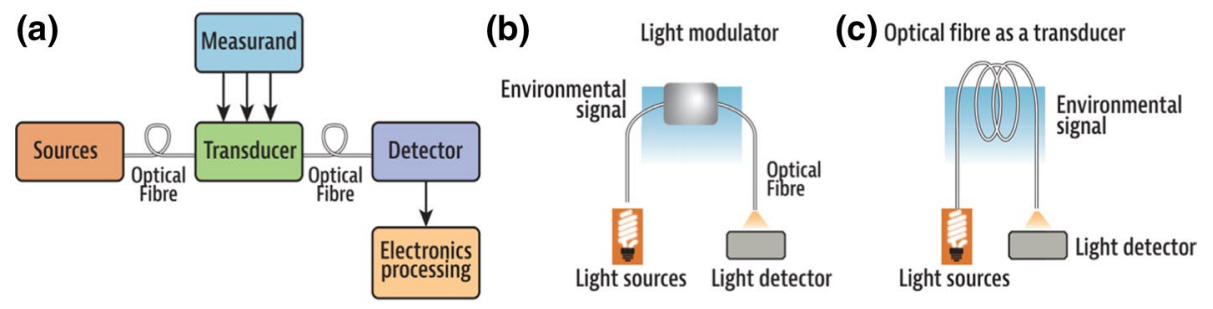

Fig. 4 Measurement principle for a fibre optic sensor (a) intrinsic (b) and extrinsic (c) fibre optic sensors. Modified from Elprocus (2019)
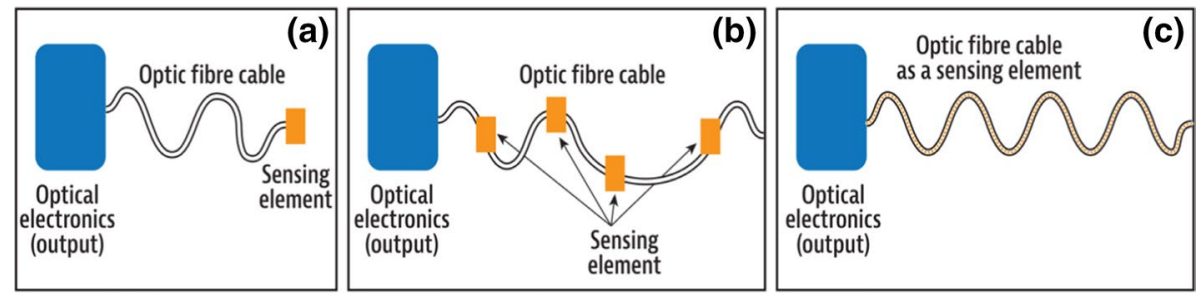

Fig. 5 Various fibre optic sensor configuration types: point fibre optic sensor (a), multiplex fibre optic sensor (b), and distributed fibre optic sensor (c) modified from Michie (2000)

characteristic, and used for diverse sensing applications. The photosensitivity indicates a fibre optic sensor's ability to induce a permanent refractive index variation in an optical fibre when exposed to radiation. The core diameter and the core, cladding and protective sheath materials of the fibre optic cable all affect the sensing system's overall sensitivity. Photosensitivity is utilised in both intrinsic and extrinsic sensor types (Fig. 4), with various techniques for probing the characteristics of light propagating through the optical fibre. These characteristics of light include intensity, polarisation, phase, frequency, wavelength, and spectral distribution (Udd 2006).

Intrinsic fibre optic sensors are modulated by an environmental signal, where the sensing between the light and the target takes place within the fibre itself. In contrast, extrinsic fibre optic sensors consist of input and output fibres carrying light to and from a light modulator (Fig. 4). In such cases, the fibre is only used as a light carrier and does not interfere with the interaction between the light and the target. These transduction mechanisms enable one to develop a variety of physical parameter detection sensors. These sensors can be configured as point sensors, multiplexed sensors where several sensors are multiplexed per channel to create a sensor network, or as distributed sensors that use the fibre optic cable as a continuous array of sensors (Fig. 5).

\subsection{Fibre Optic Geophysical Sensors}

Fibre optic sensors are generally applied as point sensors or distributed sensors in geophysics. Fibre optic geophysical sensors, which are field-tested and show improvements in several aspects of geophysical problems, are developed based on one of three types of backscattering of light (Rayleigh scattering, Brillouin scattering, Raman scattering) or fibre 
Bragg gratings (FBGs). Back-scattering-based distributed fibre optics geophysical sensors (DFOGSs) measure physical parameters along the length of the fibre. DFOGSs can vary based on the scattered light type, the sensor's operating principles, the parameters to be measured, the spatial resolution, the time needed to acquire data, the light signal applied, and other factors.

\subsubsection{Light Scattering}

When an incident light signal transmits through the fibre core, a small disruption in the environment will affect the fibre's length, diameter, and refractive index and cause the light signal to back-scatter. The changes in the characteristics of back-scattered light are the key to understand what causes the environmental changes (e.g., temperature, strain, etc.). The changes in intensity, phase, and frequency of the back-scattered signal are interpreted to determine the physical parameters' location and amplitude along the length of the fibre. By detecting changes in the amplitude, frequency, and phase of light scattered along the fibre, one can create a distributed fibre sensor for measuring localised temperature, strain, vibration, and pressure over lengths of $1 \mathrm{~m}$ to $100 \mathrm{~km}$ and more. Such measurements can be made in the time or frequency domain to resolve location information. The continuous back-scattered trace over time, where each time point corresponds to a particular location along the fibre, is converted into distance based on the speed of light in the fibre and the length of the fibre (Udd et al. 2011). Back-scattered light in a fibre optic cable has three components: Rayleigh, Stokes, and anti-Stokes. The Stokes and anti-Stokes components consist of Brillouin and Raman back-scattered light (Fig. 6). Therefore, the back-scattered light spectrum consists of three types of scattering: Rayleigh, Brillouin, and Raman (Ren 2016). The Rayleigh band has the highest intensity, followed by the Brillouin groups and then the Raman bands.

2.1.1.1 Rayleigh Scattering Rayleigh scattering is an elastic process that results from randomly occurring inhomogeneities in the refractive index of the fibre core (Fig. 7). Since this scattering is elastic, the frequency of Rayleigh scattering is equivalent to that of the incident light, but has a time delay, which is useful for spatially distributed sensing along the fibre

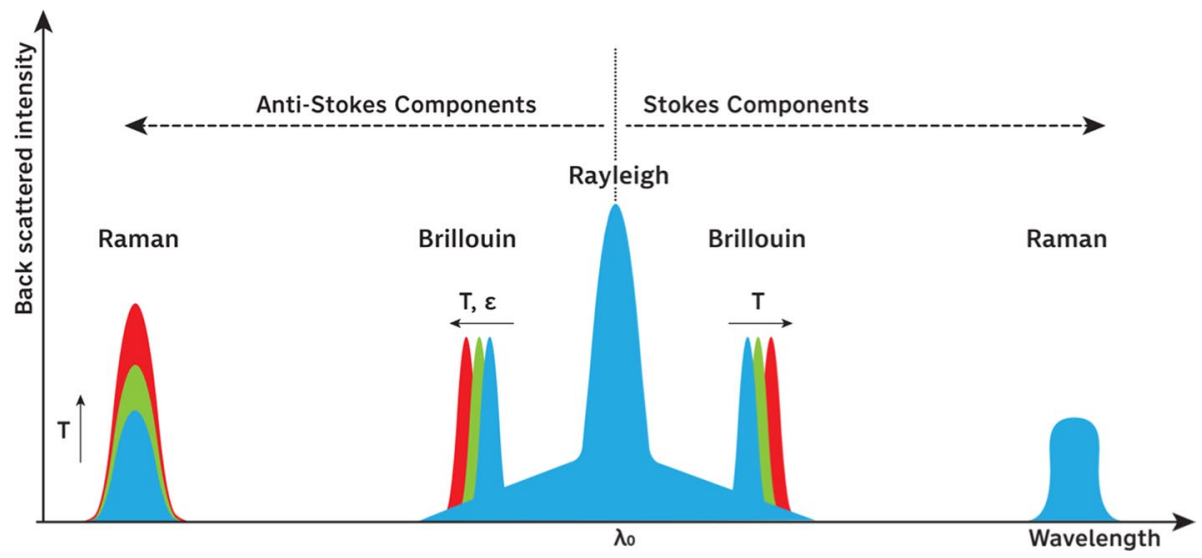

Fig. 6 Schematics of Rayleigh, Raman, and Brillouin peaks in the back-scattered light spectrum (modified from Frings and Walk 2011). T represents temperature and $\varepsilon$ is strain 
Fig. 7 Rayleigh back-scattering through the core of a fibre optic cable (modified from Jackson 2009)

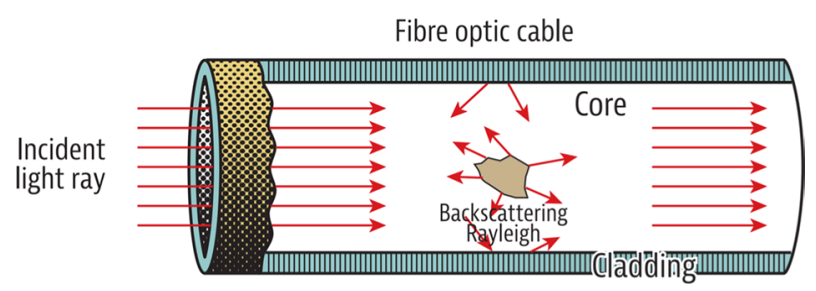

length. The DAS approach that detects acoustic waves along the fibre length is based on Rayleigh scattering. Rayleigh scattering exhibits a temperature- and strain-invariant reference attenuation distribution, useful for sensing temperature or strain via either Brillouin or Raman scattering (Liu et al. 2016; Martins et al. 2013).

2.1.1.2 Brillouin Scattering Brillouin scattering involves interactions among the incident wave, scattered wave and phonons, and a minimum frequency shift of $\sim 11 \mathrm{GHz}$ at $1530 \mathrm{~nm}$. This frequency shift for a specific incident light signal depends only on the fibre's acoustic velocity and refractive index. These parameters are determined by the fibre core composition and environmental variables. The Brillouin frequency shift, which is proportional to the medium's acoustic velocity, is dependent on the environmental conditions and demonstrates a linear relationship with temperature and strain. Therefore, the frequency shift observed in most Brillouin scattered light-based distributed sensors measures the local Brillouin shift due to the change in environmental conditions (Motil et al. 2016). The amplitude and the wavelength of Brillouin scattered light are strain and temperature-dependent. When a constant incident light wavelength source is used, the Brillouin scattering wavelength changes with temperature and strain. However, there is a slight frequency shift. The Brillouin backscattering wave and the incident wave exhibit similar attenuation. However, using a 1550$\mathrm{nm}$ light source, the spatial sensing range can be increased by minimising the loss. The Brillouin signals are approximately 15-20 dB weaker than the Rayleigh signals (Miah and Potter 2017), but they are an order of magnitude stronger than Raman signals. This enables Brillouin-based sensors to have a higher signal-to-noise ratio (SNR), improving the sensor spatial resolution and range.

2.1.1.3 Raman Scattering Raman back-scattering inside the fibre core occurs due to the back-scattering of an incident photon by a molecule. The back-scattered photon will instantaneously undergo two-state transitions by either producing or absorbing another photon. Like Brillouin scattering, Raman scattering causes a frequency shift of $\sim 13.0 \mathrm{THz}$ at $1550 \mathrm{~nm}$. Raman back-scattering depends on the laser source wavelength and is very sensitive to strain induced in the fibre due to external vibrations. Raman scattering, with one temperaturedependent component and one temperature-independent component, is primarily used in DTS systems to determine temperature changes along the fibre.

Generally, there are certain advantages using one type of back-scattered-based sensor over another depending on the detected physical parameters. For Raman peaks, the antiStokes component is temperature-dependent, while the Stokes component is virtually unaffected by temperature changes. In the case of Brillouin peaks, temperature affects both the Stokes and anti-Stokes components. Thus, Raman components are ideal for obtaining information regarding the temperature distribution along the optical fibre. The temperature does not influence the amplitude but instead causes a change in wavelength. Using the Raman peaks, one can determine the absolute temperature by analysing the ratios of the 
amplitudes of the anti-Stokes and Stokes components utilising a detector. The Brillouin peaks spread outward from the centre with an increase in temperature. They provide information about the distributed temperature and distributed strain, which both affect the wavelength shift. This information can then be deconvolved into distinct temperature and strain measurements. The Rayleigh and Brillouin scatterings have the potential for applications in distributed geophysical sensing systems to achieve simultaneous detection of temperature and acoustic parameters. A combination of Rayleigh and Brillouin scattering can be used for simultaneous measurements of vibration and temperature in single-mode fibres with a 1550-nm light source (Miah and Potter 2017). Vibration signals are more important than temperature data for subsurface mapping. Therefore, when a multi-parameter detection system is required for acoustic properties and temperature, a greater emphasis will be given to active vibration detection than temperature measurements.

\subsubsection{Fibre Bragg Gratings}

An FBG is a spatially limited periodic variation of the refractive index in the fibre optic core. In 1978, FBGs were demonstrated as a wavelength filter for the first time, based on the discovery of photosensitivity in optical fibres (Hill et al. 1978). Currently, FBGs are produced as inscribed photosensitive fibres by using an intense ultraviolet source, with a typical length of 1-10 mm. As illustrated in Fig. 8a, the periodic refractive index variation leads to an effect like Bragg reflection in atomic crystal layers at a wavelength related to the structure's periodicity. When light is incident upon the FBGs, only a portion of the incident light intensity (I) at a wavelength $\lambda$, in which $\lambda$ is proportional to the period (d) of the refractive index variation, will be reflected (Fig. 8a). The reflected wavelength will change if the periodicity or refractive index changes (Fig. 8b), enabling the use of FBGs as a sensor. The changes in fibre length due to the temperature or applied strain of the fibre (Fig. 8c) will change the periodicity to a value of $d^{\prime}$, which will lead to a corresponding change in reflected wavelength. Similarly, pressure can be measured by connecting the FBG to a membrane (Fig. 8d). Therefore, FBGs are applied to sense and monitor strain, temperature, and pressure.

FBG sensors are applied as point sensors that can be distributed along the length of a fibre. An FBG system's characteristic to reflect only part of the energy in a limited wavelength band around its peak wavelength, and allow the remaining energy to pass through it,

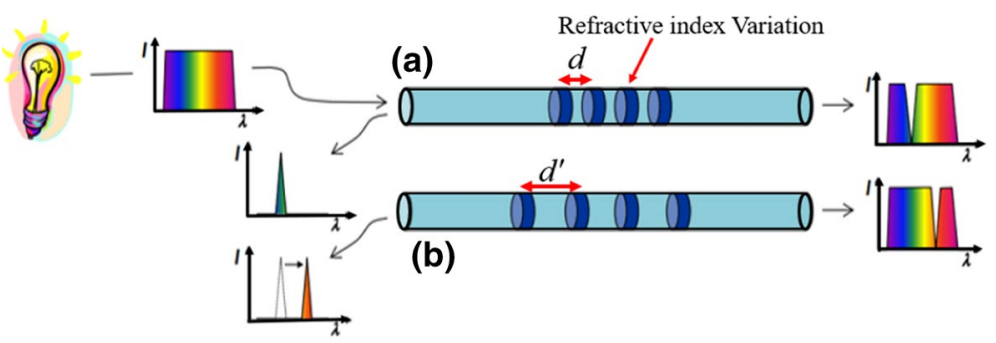

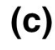

(c)

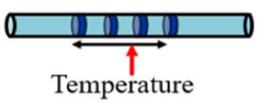

(d)

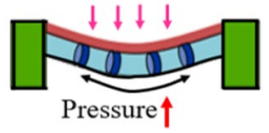

Fig. 8 Working principle of FBG-based fibre optic sensors (modified from Lumens 2014) 
helps develop multiplexed fibre optics geophysical sensors. This feature enables multiple FBG sensors to be incorporated into a single optical fibre by wavelength division multiplexing (WDM), where FBGs with different peak wavelengths are used for each sensor (Hecht 2002). Multiplexed FBG sensors measure physical parameters along the fibre length at a finite number of locations by multiplexing several sensors in the wavelength domain (López-Higuera 1998). Multiplexing FBGs beyond 100 FBGs in the wavelength domain will not extend the sensing element, but an increase in FBG number and sensing length can be achieved by applying time-domain multiplexing (Barrias et al. 2016). The time-division multiplexing (TDM) scheme distinguishes the sensors by the time of flight of a short interrogation pulse.

\subsubsection{The Technology and Characteristics of Commonly Applied DFOGSs}

Numerous DFOGSs have been developed using different technologies designed to suit different geophysical problems and the variations in back-scattered light. The most common field-tested and applied DFOGS types are Brillouin-scattering-based sensors [optical time-domain analysis (BOTDA) and optical time-domain reflectometry (BOTDR)], Raman-scattering-based sensors (OTDR), Rayleigh-scattering-based sensors [optical frequency-domain reflectometry (OFDR) and phase optical time-domain reflectometry (phase OTDR)], and FBG-based sensors. These sensors differ in several aspects, even for a single type of back-scattering of light. For example, the BOTDA sensor is based on stimulated Brillouin scattering, while the BOTDR sensor is based on spontaneous Brillouin scattering. The BOTDA technique uses two counter-propagating lasers and takes advantage of Brillouin amplification (Bao and Chen 2011), using direct detection schemes (Fig. 9). When the BOTDA system is functioning, as indicated in Fig. 9, an optical pump and a probe that supplies a continuous wave $(\mathrm{CW})$ are counter-propagating along the sensing optical fibre so that the optical frequency differences are scanned for the frequency shift. The acquired Brillouin spectrum is processed further using data processing techniques to find the peak locations of Brillouin frequency ( $\mathrm{Lu}$ et al. 2019b).

There are limitations in sensing ranges and spatial resolutions of these two types of Brillouin back-scattered light-based fibre optic sensors. There have been works to improve the spatial resolution of BOTDA temperature sensors, and a $2 \mathrm{~cm}$ resolution is achieved by Dong et al. 2012 at a minimal sensing range that extends up to $2 \mathrm{~km}$. The BOTDA strain sensors are limited to a spatial resolution of roughly $1 \mathrm{~m}$ (Barrias et al. 2016). In practical field measurements using Brillouin back-scattering-based distributed sensors, it is possible to measure a strain with a resolution of a few micrometres over one metre sensing range and a temperature resolution of less than $1{ }^{\circ} \mathrm{C}$ (Bao and Chen 2011). The measurand resolution can be increased by further processing the acquired data. It is possible to obtain a

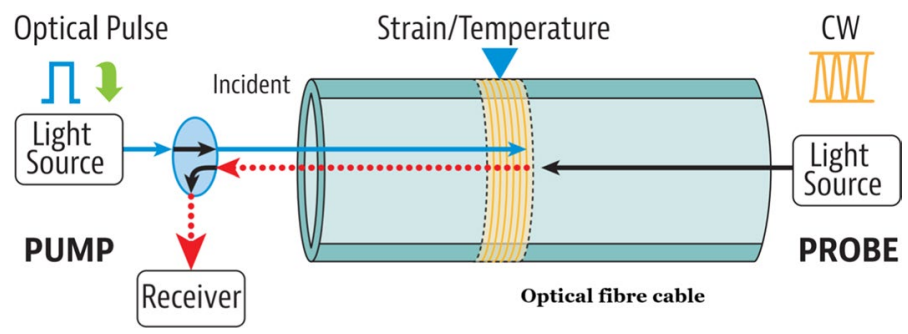

Fig. 9 Schematic diagram of the BOTDA sensing scheme (modified from Xue et al. 2018) 
temperature resolution of $0.1{ }^{\circ} \mathrm{C}$, by processing DTS data, at well depths of up to $5 \mathrm{~km}$ (Brown and Hartog 2002). The Rayleigh back-scattering light-based OFDR sensors have a millimetre spatial resolution (Froggatt and Moore 1998), but they have not been achieved at their current maximum sensing range that extends to $50-70 \mathrm{~km}$. Similarly, a $2 \mathrm{~mm}$ spatial resolution is achieved using FBG-based sensors (Ferdinand 2014), while extending the sensing range remains a challenge. A comparison of the relative performance of these four types of DFOGS technologies applied in different geophysical applications is presented in Table 1.

Different performance parameters are preferred by individual users for each application, depending on their needs and requirements. Hartog (2017) outlined the evaluation parameters for distributed fibre optics sensors' performance, namely measurement resolution, spatial resolution, sensing range, and measurement time. The four parameters are independent, with trade-offs making up the whole system's performance. The improvement of one factor often necessitates a compromise in another. For example, OTDR systems can measure over $100 \mathrm{~km}$ with a spatial resolution of several metres. The OFDR can achieve millimetre resolution, while its sensing distance is usually limited (Yuksel et al. 2009). SNR is the vital factor linking the interdependence of the four parameters. It directly determines the measurement resolution and finally limits the spatial resolution, sensing distance, and measurement average time (Hartog 2017).

At present, DFOGSs are an attractive technology that offers superior performance and advantages over conventional wireline geophysical sensors. These sensors are ideal for applications in which reliability in a changing environment is essential. DFOGSs will become more accustomed and cost-effective in the future when new technology becomes more familiar. Sensor-producing companies are addressing multiple market segments, and current energy companies are the dominant market. The simultaneous fibre optics sensor systems, comprising DAS systems compatible with DTS systems using the same optical fibre cables, showed significant market penetration powers (Muanenda 2018). The distributed fibre optic sensor (DFOS) market analysis for 2014-2025 by Research and Markets (2017) indicated that the oil and gas market alone would have an increase of $19 \%$ in total.

\section{Application of Fibre Optics Sensors in Geophysical Studies}

The use of fibre optic sensors in geophysics began in the oil and gas industry, with a fibre optic pressure sensor applied in a well in 1993 (Baldwin 2014). Subsequently, fibre optic sensors have been employed as temperature and pressure gauges to monitor unconventional reservoirs and enhanced hydrocarbon recovery (Rehman and Mendez 2012). Therefore, single-point fibre optics sensors, installed at the end of the fibre optic cable, were the first to be applied in the oil and gas industry for pressure and temperature measurements in the 1990s. Numerous point sensors are placed at multiple points along the fibre to make quasidistributed sensors ( $\mathrm{Li}$ et al. 2015). Although the use of fibre optic sensors is less common than that of other conventional geophysical techniques (electrical, magnetic, seismic, etc.), their geophysical application is in progress, particularly as distributed sensors (DAS, DTS, DPS) and simultaneous detection of multi-physical parameters. Field experiments on the fibre optic cable enable different fibre cable schemes for high-power and high-definition live camera data transmission mechanisms inside a borehole. 


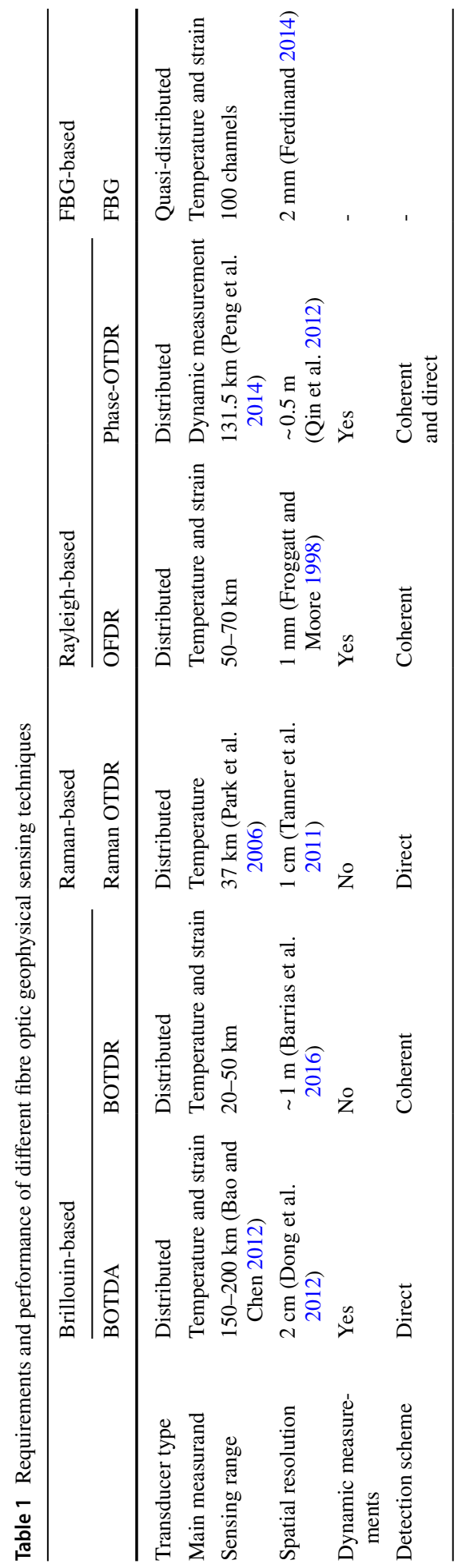




\subsection{Distributed Acoustics Sensors (DAS)}

DAS is a fibre optic geophysical technique that deploys fibre optic cable instead of conventional geophones to record acoustic signals. It works by interrogating the Rayleigh back-scattered signals caused by the strain along the fibre optic cable due to the propagation of seismic waves (Molenaar 2013). The channels that sense elastic waves in the fibre optic cables are at a specified distance so that DAS can be used as an array of designed 1-component geophones to measure deformations along the fibre length. It resembles an array of geophones with higher density along its length. The spacing between adjacent receivers and the fibre's sensing length is generally determined before the survey. The light pulse generating rate is much higher than a seismic frequency, typically in the range of $10-100 \mathrm{kHz}$ with the possibility to be regulated with a high rate corresponding to high SNRs and vice versa ( $\mathrm{Li}$ et al. 2015).

DAS is a relatively well-established fibre optics sensing method in geophysical surveys, especially in a borehole survey environment in the form of vertical seismic profiling (VSP). Initially, a DAS VSP's field experiment was tested by Shell Canada in 2009, followed by the test of Mestayer et al. (2011) for its capability to replace conventional geophones. The results of DAS VSPs are either compared to traditional VSP surveys or validated by experimental results (Jreij et al. 2018; Ghahfarokhi et al. 2018; Reinsch et al. 2015). Companies that tested DAS systems of 3D multi-well VSP, deep water time-lapse VSP, and low-footprint monitoring included Silixa (Parker et al. 2013; Daley et al. 2013), OptaSense (Mestayer et al. 2012), Schlumberger (Barberan et al. 2012), and Halliburton (Barfoot 2013). DAS has been applied for single-parameter detection in a borehole (Bakku et al. 2014a, b; Harris 2017; Li et al. 2015; Nesladek 2017; Silkina 2014) and has provided high-resolution data for the energy and environmental sectors (Daley et al. 2013, 2016; Dean et al. 2015). DAS and geophone VSP data by Mestayer et al. (2011) are compared in Fig. 10. At the beginning of the data recording times, the DAS and geophone systems receive a similar signal, while as time goes by, more noise is recorded in the DAS system than the geophone system. The velocity profile obtained from DAS VSP matched well with the geophone VSP

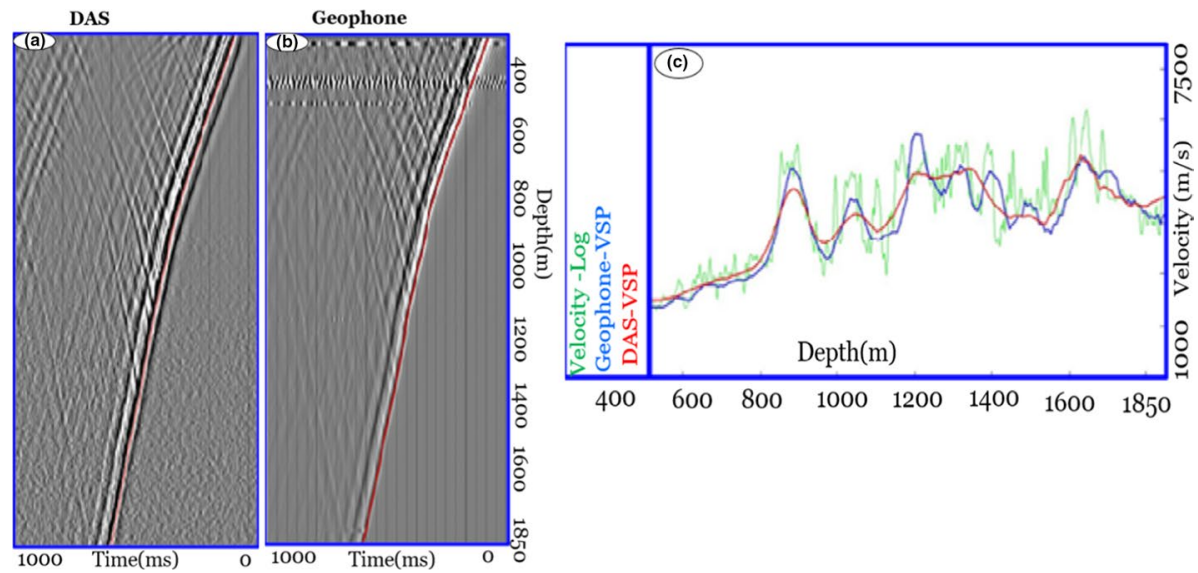

Fig. 10 A comparison of the seismic signal recorded by DAS VSP (a), conventional geophone VSP (b), a velocity profile comparison between DAS VSP (red), geophone VSP (blue), and sonic logging (green) (c) modified from Mestayer et al. (2011) 
and the sonic log velocity profiles demonstrating DAS's capability to replace conventional geophone VSPs and the sonic log measuring system.

The recent developments in fibre optic sensing systems by the Silixa company will potentially increase the applications of DAS VSP for permanent reservoir monitoring and 4D seismic VSP recording. Silixa developed a high-resolution advanced DAS system called 'Carina' with precision-engineered constellation fibre optic cable having 100x $(20 \mathrm{~dB})$ improved back-scatter light compared to that of standard fibre (Naldrett et al. 2020). The new system has high sensitivity, wide dynamic range, broadband, and wideaperture response that benefits from acquiring high-resolution 4D seismic images. The VSP data were acquired using a 15-level conventional geophone array at 11 data positions along the wellbore and using a DAS Carina sensing system by installing the improved fibre optic cable cemented behind the casing simultaneously (Fig. 11). The field test result showed that the enhanced DAS system recorded high-resolution images along the entire depth of the wellbore compared to the geophone VSP data.

DAS has been applied in microseismic measurements, well and reservoir surveillance, hydraulic fracturing monitoring, and diagnostics, earthquake detection, and potentially has excellent capability to replace conventional geophones and seismometers (Bakku et al. 2014a, b; Lindsey et al. 2017). The DAS capability for reservoir monitoring showed that DAS presents enough repeatability for time-lapse applications (Harris 2017; Naldrett et al. 2020). Molenaar (2013) explained that DAS is useful in both open, cased, and cemented boreholes, hydraulic fracturing monitoring, and diagnostics providing essential information about boreholes such as a quantitative assessment of injection rates and injection fluids. DAS presents information on the estimation of production profiles, injection profiles, multi-phase flow, well-integrity, and production monitoring (Li et al. 2015) for wells and reservoir surveillance. Besides borehole survey and reservoir monitoring, DAS is applied in near-surface and ocean bottom seismic wave detections. Field tests have used the
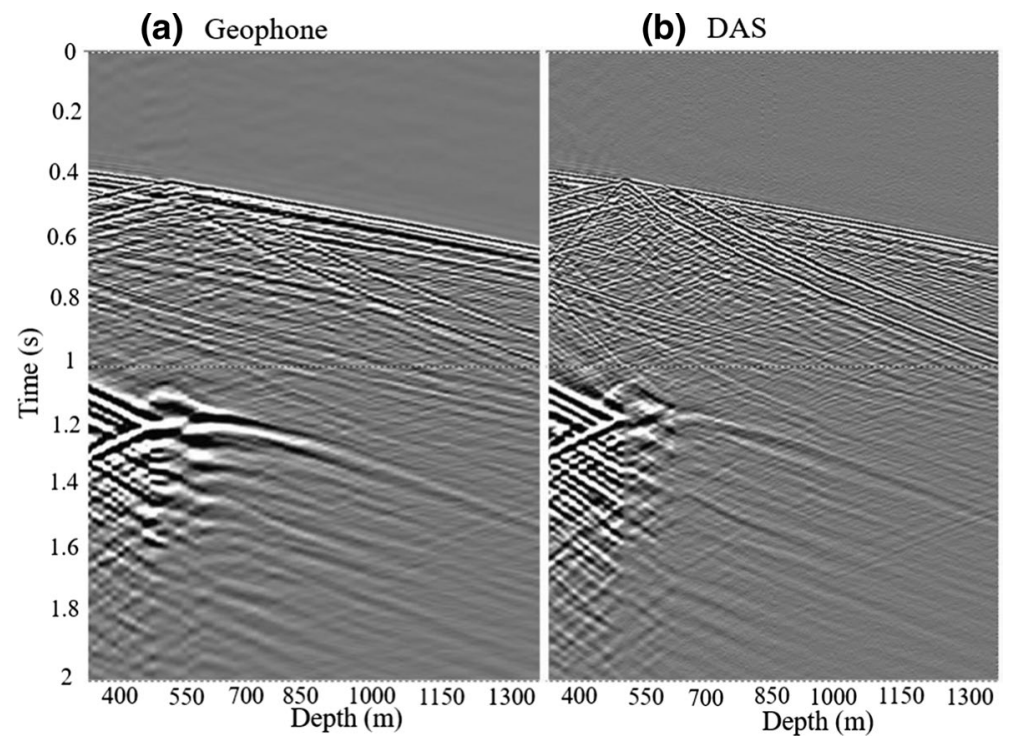

Fig. 11 A comparison of a seismic signal record along with the entire depth of the wellbore. Stacks of five shots at 11 tool positions recorded using conventional geophones (a) and stacks of 5 shots recorded using a DAS Carina system (b) modified from Naldrett et al. (2020) 
standard telecom fibre optic cable networks buried below ground and ocean bottoms as active and passive seismic wave detectors. The $\mathrm{p}$ - and s-waves can be identified from nearsurface earthquake sources.

Conventional seismometer coverage is limited to a handful of permanent ocean bottom stations. Recent experiments based on fibre optic telecom cables on the ocean floor, called dark fibres, present a promising method for detecting earthquakes. Marra et al. (2018) detected earthquakes over 75-535 km, with epicentre distances ranging from 25 to $18,500 \mathrm{~km}$. In a near-surface study using fibre optic cables, Jousset et al. (2018) measured the dynamic strain from earthquake waves of both natural and man-made origin. The authors collected strain data with a spacing of $4 \mathrm{~m}$ along a $15 \mathrm{~km}$ fibre optic cable system on the Reykjanes Peninsula in southwest Iceland, identifying structural features such as normal faults and volcanic dykes. Research conducted at Stanford University demonstrated that fibre optic cables could continuously monitor seismic conditions and earthquakes (Tech 2018). The DAS near-surface seismic survey measures active seismic waves deploying the fibre optic cable at $0.8 \mathrm{~m}$ depth below the surface in a similar manner to geophone survey lines (Pevzner et al. 2017). DAS surveys have also been applied to study hydrological changes in basins, with shallow structural mapping and groundwater depth determination (Ajo-franklin et al. 2019). Thus, fibre optic sensors are considered essential tools for the future of both near-surface seismic surveys and seismology.

The use of DAS in all geophysical applications offers certain advantages over geophones and hydrophones. Its use, particularly in borehole seismic surveys, has benefits such as long equipment survivability, dense spatial sampling, and full well coverage, making it uniquely suited for permanent reservoir monitoring (Correa et al. 2019). It has numerous advantages compared to conventional 1-component geophones. It can be used in various well types (e.g. horizontal well or ultra-slim well) due to its slim cable, and the fibre cable is easily installed together with other optical fibre sensors like DTS and DPS. Unlike a geophone, DAS can obtain measurements with complete vertical coverage of a well without fibre movements. DAS is non-intrusive, which means it can be used in an exploration well, production well, and observation well without postponing production.

Although DAS has several advantages compared to conventional geophones and is a rapidly developing technology, limitations might hinder its widespread application. This may include low SNR, uncertainty in channel depth, lack of transverse sensitivity, difficulties in determining the optimum gauge length, and only one-component measurements. There have been tests to reduce these limitations and apply DAS technology more widely. These include de-noising data processing techniques using a band-pass filter, median filter, and stacking of multiple fibre optic measurements that can remove the time-variant noise generated from temperature fluctuations in the well and optical noise (Bakku et al. 2014a, b). A helically wrapped cable (HWC) design was introduced to improve the fibre optic cable's transverse sensitivity and broad-side wave detections (Hornman et al. 2013). Its fibre arrangement has been theoretically described by Kuvshinov (2016) and tested in field experiments by Hornman (2017). The recent work by Silixa (Naldrett et al. 2020) achieved DAS data with 100 times better SNRs than ordinary fibre cable. Moreover, the accurate determination of DAS's receiver channel depth using tube wave reflections and check shots is a useful method to calibrate the receiver channels in-depth (Li et al. 2015). There has been progress to express the optimum gauge length prior to the DAS survey as it affects both SNR and resolution of DAS data (Bakku et al. 2014a, b; Dean et al. 2016; Li et al. 2015; Yang et al. 2019). 


\subsubsection{DAS Gauge Length}

DAS data quality is affected by the length of the sensing part of the fibre optic cable called the gauge length (L). The strain measurement in distributed fibre optics sensing cable is not at individual points like point sensors or conventional geophones; instead, it is acquired across a gauge length of the fibre. The strain is summed along the gauge length and defined in the digital rather than the optical domain (Dean et al. 2015). The underlying principle behind COTDR operation is to analyse the phase difference between the back-scattered signals from two points separated by a gauge length (Bakku et al. 2014a, b; Li et al. 2015). An axial strain is obtained by analysing the perturbed phase difference between back-scattered lights from two points (Ning and Sava 2018). The phase lag is interrogated everywhere along the fibre, enabling the whole fibre to become a sensor (Fig. 12). When data are acquired using DAS systems, the signal due to the light pulse's first emission is backscatted at the front and end of the gauge length $\left(S_{1}\right.$ and $\left.S_{2}\right)$, and its sum for unstrained fibre is $S_{1}+S_{2}$. When the fibre is strained, the sensing part will be changed by $\Delta L$, and the gauge length will become $L+\Delta L$ so that the corresponding back-scattered signal at the front and end of the gauge length for the strained fibre will be $S_{1}^{\prime}+S_{2}^{\prime}$. The analysis of the phase lag between $S_{1}+S_{2}$ and $S_{1}^{\prime}+S_{2}^{\prime}$ enables one to obtain the strain along the fibre.

A larger gauge length corresponds to better SNR but lower spatial resolution and vice versa (Bakku et al. 2014a, b). If too large a gauge length is used, the resolution will be reduced, and the wavelet's shape will be distorted (Dean et al. 2016). Numerous DAS works used different gauge length values: $1 \mathrm{~m}$ (Ning and Sava 2018; Daley et al. 2013), 10 m (Fernández-Ruiz et al. 2020), and achieved acceptable SNR. Farhadiroushan et al. (2016) showed that the gauge length can be reduced to $5 \mathrm{~cm}$ while maintaining a sufficient SNR using specifically designed optical fibres. The choice of the most suitable sensing gauge length, called the optimum gauge length $\left(L_{\mathrm{opt}}\right)$ that considered both SNR and resolution effects, is essential and should be made before DAS data acquisition. The works by Dean et al. (2015), Dean et al. (2016), and Yang et al. (2019) used the concept of Ricker wavelet as a better representation of seismic wave/strain and its temporal and spatial wavelength to drive the formula that better represents the $L_{\text {opt }}$ of straight fibre optic cable. According to these works, a seismic wave is represented by a Ricker wavelet in the time domain as:
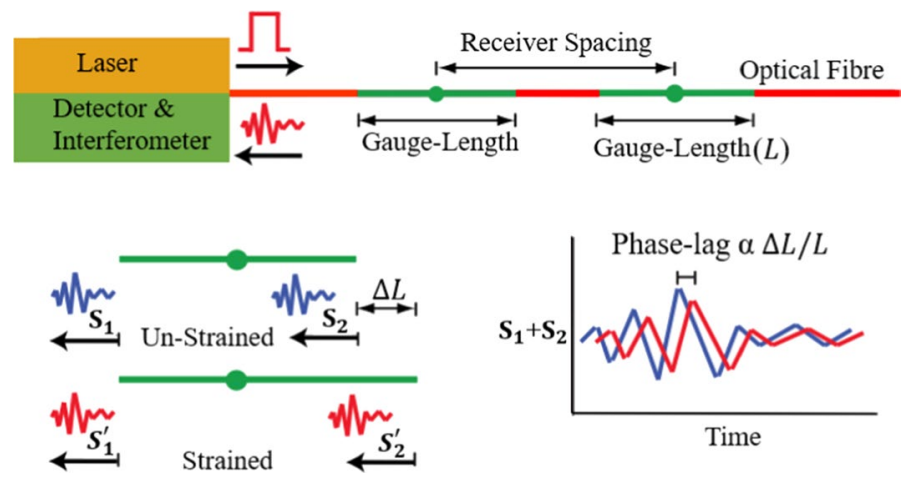

Fig. 12 The gauge length in the DAS system (Bakku et al. 2014b). The receiver spacing, also called channel spacing, refers to the distance between consecutive average strain measurements within a gauge length (modified from Ning and Sava 2018) 


$$
R(t)=\left(1-2 \pi^{2} f_{p}^{2} t^{2}\right) e^{-\pi^{2} f_{p}^{2} t^{2}}
$$

where $f_{p}$ is the peak frequency. A Ricker wavelet that travels with velocity $v$ is expressed in the space domain as:

$$
R(x)=\left(1-2 \pi^{2} k^{2} x^{2}\right) e^{-\pi^{2} k^{2} x^{2}}
$$

where $\kappa=\frac{(\sqrt{6 / \pi)}}{v \lambda_{t}}$ is the wavenumber. The spatial wavelength of the wave $\left(\lambda_{s}\right)$ that represents the distances between two minima in the space domain is related to the temporal wavelength $\left(\lambda_{t}\right)$ as $\lambda_{s}=v \lambda_{t}$. The graphical presentations of the Ricker wavelet in the time domain are given in Fig. 13(a).

Dean et al. (2016) expressed the strain $(\varepsilon)$ applied on the fibre due to the Ricker wavelet that propagates in the $x$-direction with velocity $\nu$ in the time domain as:

$$
\varepsilon(t, x)=\left(1-2 \pi^{2} f_{p}^{2}\left(t-\frac{x}{v}\right)^{2}\right) e^{-\pi^{2} f_{p}^{2}\left(t+\frac{x}{v}\right)^{2}}
$$

The total change in the fibre length $(\Delta L)$ due to the applied strain at position $x$ that in turn causes a change in the phase of the back-scattered light is equal to the integral of the strain along its lengthand the strain measured by the fibre is given by

$$
\begin{gathered}
\left.\Delta L=\int_{-\frac{L}{2}}^{\frac{L}{2}} \varepsilon(t, x)=\int_{-\frac{L}{2}}^{\frac{L}{2}}\left(1-2 \pi^{2} \kappa^{2} x^{2}\right) e^{-\pi^{2} \kappa^{2} x^{2}} \mathrm{~d} x=x e^{-\pi^{2} \kappa^{2} x^{2}}\right]_{-\frac{L}{2}}^{\frac{L}{2}} \\
\Delta L=L e^{-\pi^{2} \kappa^{2} \frac{L^{2}}{4}} \\
\varepsilon_{\text {fibre }}=\frac{\Delta L}{L}
\end{gathered}
$$

(a)

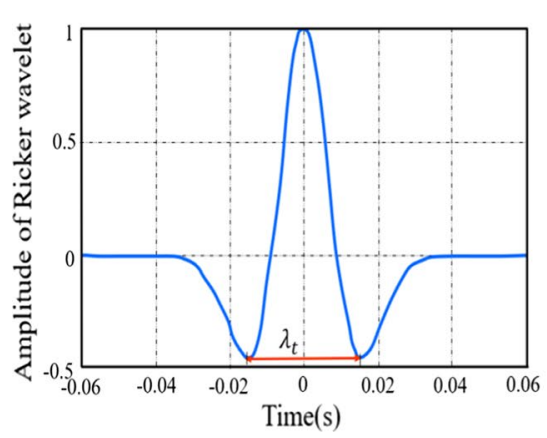

(b)

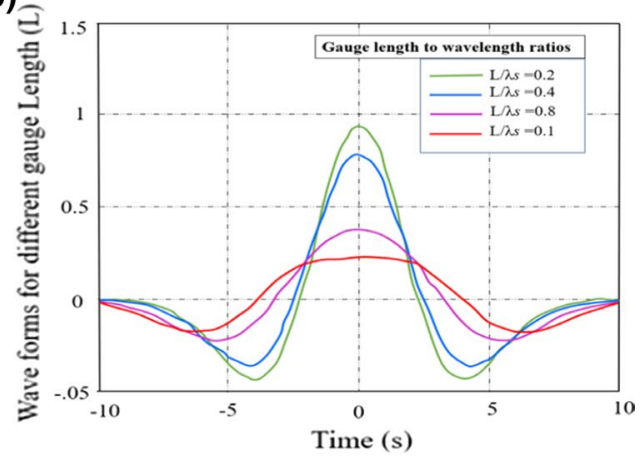

Fig. 13 The Ricker wavelet curve in the time domain (a) and gauge length-to-temporal wavelength ratio curves (b) (modified from Yang et al. 2019). The horizontal time between two minima represented by the red line is the Ricker wavelet's temporal wavelength $\left(\lambda_{t}\right)$ in the time domain 
Therefore, as the gauge length gets smaller, the value of strain measured by the fibre approaches the maximum amplitude of the actual strain (i.e. as $L \rightarrow 0, \varepsilon_{\text {fibre }} \rightarrow \varepsilon_{\max }$ ). The maximum value of $\Delta L\left(L_{\max }=L e^{-\pi^{2} \kappa^{2} \frac{L^{2}}{4}}\right)$ occurs when the gauge length $(L)$ is equal to $\lambda_{s} / \sqrt{3}$ implying that the maximum strain will be measured when the gauge length is as small as possible. Likewise, the error in the measured strain $\left(E\left(\varepsilon_{f}\right)\right)$ is given by;

$$
\left(E\left(\varepsilon_{f}\right)\right)=\frac{E(\Delta L)}{L}
$$

and the corresponding SNR on the measured strain data is given by

$$
\mathrm{SNR}=\frac{\Delta L / L}{E\left(\frac{\Delta L}{L}\right)}=\frac{\Delta L}{E(\Delta L)}
$$

Therefore, the peak SNR value will occur where the value of $\Delta \mathrm{L}$ is a maximum (i.e. when the gauge length/spatial wavelength $=1 / \sqrt{3}$ ).

Furthermore, the graphical relationship between the gauge length-to-spatial wavelength ratio (Fig. 14) and the resulting waveforms for different gauge length values indicates that the waveforms become more distorted as the gauge length-to-wavelength ratio increases. When the gauge length is larger than the spatial wavelength (ratio $>1$ ), the maximum value is no longer located where the centre of the gauge length coincides with the centre of the wavelet. The optimum gauge length determination requires close observation of the relationships of SNR and resolution with gauge length values. The graph of SNR versus gauge length-to-spatial wavelength ratio indicates that values between 0.40 and 0.77 represent the range of ratios where SNR $>90 \%$ of the maximum (Fig. 14a). This is the range of values where the resolution values should be included. Dean et al. (2016) used the resulting wavelength (as a proxy to resolution) versus gauge length to spatial wavelength (Fig. 14b) to perceive the resolution effect. The green line indicates the gauge length-to-spatial wavelength ratio is $50 \%$ and the resulting wavelength values where the wavelength is $15 \%$ of the actual wavelength (Dean et al. 2016; Yang et al. 2019). According to these values, the overlap between the two sections, where the SNR is greater than $90 \%$ of maxima and deviation of the resulting wavelength is lower than $15 \%$, occurs at the optimal gauge length-to-spatial wavelet ratio values 0.402 and 0.54 . Therefore, the optimal gauge length is expressed

Fig. 14 The effect of gauge length-to-spatial wavelength ratio on the SNR (a) and resulting wavelength deviation (b) (modified from Dean et al. 2016)
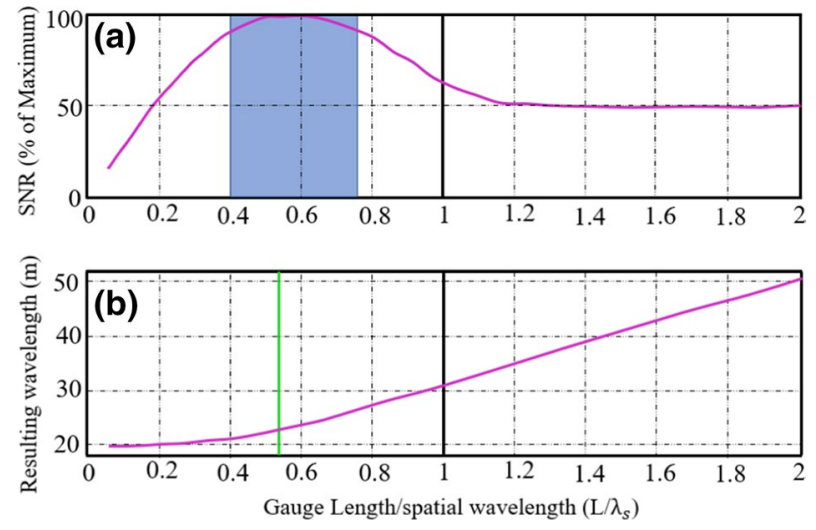
by optimal ratio values between 0.402 and 0.54 , and spatial wavelength $\left(\lambda_{s}\right)$ of the Ricker wavelet is given by:

$$
L_{\mathrm{opt}}=\frac{\text { ratiov }}{f_{p}}=\operatorname{ratio} \times \lambda_{s}
$$

where ratio represents the desired gauge length-to-spatial wavelength ratio (Dean et al. 2016; Yang et al. 2019).

If the attributes vary considerably along the survey line during DAS data acquisition, multiple gauge lengths can be used (Dean et al. 2016). Furthermore, the strain detection by HWC is different from the straight fibre, and the optimum gauge length expression is different. Yang et al. (2019) conducted a theoretical analysis of optimal gauge length determinations for DAS measurements using HWC, though it remains to be confirmed with actual field experiment results. The work proposed an optimum gauge length expression that considers SNR and resolution as:

$$
L_{\mathrm{opt}(\mathrm{HWC})}=\frac{\operatorname{ratio} \times \lambda_{s}}{\sin \alpha \cos \theta}
$$

where the ratio value varies from 0.402 to 0.5 , similar to straight fibre, $\alpha$ is the fibre cable's wrapping angle, and $\theta$ is the incident angle for a situation where the impinging Ricker wavelet does not travel along the HWC and creates an incident angle of $\theta$.

\subsection{Distributed Temperature Sensors (DTS)}

DTS is the second most commonly applied fibre optic sensing system in geophysical applications. These sensors are applied to measure temperature mainly within a borehole survey environment in the energy and environmental sectors. Studies have reported the use of DTSs in boreholes (for example, Patterson et al. 2018; Read et al. 2015; Siska et al. 2016; Zhang et al. 2018a, b). DTS systems are beneficial for temperature measurements in harsh environments that require rugged designs. DTSs have been applied in environments with working temperatures of $300{ }^{\circ} \mathrm{C}$, and others with pressures exceeding 20,000 psi (1379 bar) (Baldwin 2014). The high-temperature regenerated fibre Bragg gratings (FBGs), inscribed in high-attenuation fibres and standard telecom fibres as temperature sensors, are used to measure heat transfer optically powered by heating elements induced by gas flow for temperatures ranging from room temperature to $800{ }^{\circ} \mathrm{C}$ (Chen et al. 2014). DTSs are not limited to measuring temperature values, but also as a distributed borehole flowmeter. The flowmeter consists of an armoured fibre optic cable and utilises the active DTS (ADTS) technique, where the difference in temperature between a heated and unheated cable is a function of the fluid velocity. For example, based on the ADTS technique of flowmeter design, an increase in flow velocity from 0.01 to $0.3 \mathrm{~m} / \mathrm{s}^{2}$ elicited a $2.5^{\circ} \mathrm{C}$ cooling effect in a fractured rock aquifer (Read et al. 2014).

\subsection{Distributed Pressure Sensors (DPS)}

Fibre optic sensors have been used to detect pressure over the past two decades in the energy and environmental sectors. Masoudi et al. (2013) measured a dynamic strain perturbation along $1 \mathrm{~km}$ of a single-mode telecom fibre with a spatial resolution of $2 \mathrm{~m}$ over a frequency range of 500-5000 Hz. Additionally, Domingues et al. (2018) demonstrated 
the possibility of manufacturing a cost-effective fibre optic pressure sensor based on intrinsic Fabry-Perot interferometric microcavities. This fibre optic pressure sensor can monitor pressures up to $900 \mathrm{kPa}$, with sensitivities reaching 59.39 $\pm 1.7 \mathrm{pm} / \mathrm{kPa}$. Yang et al. (2018) demonstrated a gas pressure sensor based on an anti-resonant reflectance guidance mechanism in a quartz capillary tube with an open cavity. This fibre optic pressure sensor had a sensitivity of $4.278 \mathrm{~nm} / \mathrm{MPa}$.

\subsection{Simultaneous Detection of Multi-parameters}

Recent potential applications of DFOFs have been to detect more than two parameters simultaneously in a borehole. For example, DAS has been combined with DTS, also known as hybrid acoustics and temperature sensing (Miah and Potter 2017; Muanenda et al. 2016), and distributed strain and temperature measurements have been combined (Masoudi et al. 2013; Muanenda et al. 2016; Yahei et al. 2009). A hybrid distributed acoustic and temperature sensor (DATS), using a standard single-mode fibre optic cable, was reported to measure temperatures with an accuracy of less than $0.5^{\circ} \mathrm{C}$ at a spatial resolution of $5 \mathrm{~m}$ (Muanenda et al. 2016). Three parameters have also been simultaneously measured in boreholes, using a multi-parameter distributed fibre optic sensing system for strain, temperature, and vibration (Zhang et al. 2016), and a method for microseismicity, strain, and temperature during hydraulic fracturing (Karrenbach et al. 2019).

A DTS log well intervention methodology developed by the Ziebel company known as 'Ziebel ZipLog' has a DTS cable within a carbon rod. It has been employed to measure production and injection wells' temperature, especially in horizontal wells with up to a $90^{\circ}$, bend for reservoir monitoring (Fig. 15a). The Ziplog technology enabled one to detect the horizontal inflow and injection allocation in wells (Hansen et al. 2009) and was later improved to incorporate six fibre optic cables (Danardatu et al. 2014). The improved semistiff carbon rod contains two multi-mode fibres for DTS, one single-mode fibre for DAS, three single-mode fibres for point pressure, point temperature, and vibration measurements (Fig. 15b). Assembling the point pressure and temperature sensors at the bottom of the hole, the company conducted a field trial in a horizontal well and obtained temperature and acoustic data, in conjunction with bottom hole data, that gave comprehensive information for real-time surveillance and dynamic well analysis (Danardatu et al. 2014).

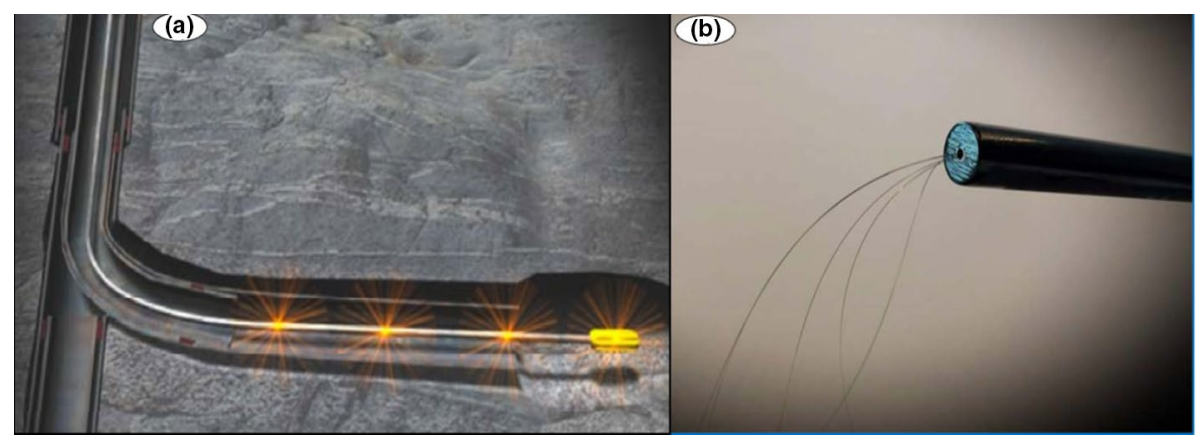

Fig. 15 (a) The Ziebel Ziplog DTS system in a highly deviated well (modified from Hansen et al. 2009) and (b) a semi-stiff carbon rod with six fibre optic cables to record multiple data at a time (modified from Danardatu et al. 2014) 
Integrating the different measurements obtained simultaneously helps to monitor the well conditions better. DAS and DTS's combined data gathered from the same well offer the best use of that information to monitor the well's conditions for its life. For example, during hydraulic fracturing of an unconventional well, DTS is used for geothermal acquisition, cement monitoring, and perforation monitoring. DTS data as a thermal tracer can be used to identify the injection profile and augment the temperature profiles obtained by DTS with those from DAS. Moreover, DAS can be used to get DAS VSP data along the well and can provide data to monitor offset wells that are being fractured (Silkina 2014). Thus, fibre optic sensor integration to detect more than two parameters simultaneously is advantageous.

\subsection{High energy Transmission and Downhole Camera}

Fibre optic cables can transmit an enormous amount of energy, reaching $50 \mathrm{~kW}$, for downhole studies requiring high energy inputs, which cannot be accommodated by conventional wirelines. Fibre optic cables are also used in downhole laser cutting technology, a costeffective alternative for cutting production tubes, casing, and drilling pipes. They provide downhole laser pipe cutting technology with real-time feedback on the cutting process and cutting depth control for preventing damage to the outer pipes. These applications are enabled by armoured optical fibre cables that are resistant to mechanical and chemical damage caused by energy transmission. Armoured fibre cables can transmit information at a speed of $6000 \mathrm{Mbit} / \mathrm{s}$, which is approximately 100 times faster than standard wireline cables. However, these cables cannot be used as distributed sensors due to their reduced sensitivity. Fibre optics has recently been applied in hard-scale mineralization build-up, laser removal technology to remove hard scales from production tubing, and downhole cameras (Zerlux 2019). The downhole camera application of single-mode fibre optic cables allows visual inspection within the wellbore, even in low visibility and extreme wellbore conditions of up to $180{ }^{\circ} \mathrm{C}$ and 10,000 Psi (690 bar). The presence of fibre cables and the development of technology in digital data compression enables the transmission of colour and live full high definition (HD) videos at borehole depths of up to $6000 \mathrm{~m}$ (Zerlux 2019).

\section{Limitations, Challenges, and Future Possibilities}

\subsection{Limitations}

The new geophysical techniques based on fibre optic sensors are still under development in cables, sensors, field measurements, and data processing techniques. The development of specific methods, such as DTS and DAS, primarily occurs at technical universities, telecom industrial entities, oil and gas industrial entities, and research institutes. The standard optic fibres, both single mode and multi-mode, used for sensing and data transmission in geophysical applications, require improvements to pass light within them with minimum reflection, scattering, and attenuation. It is difficult to distinguish between changes in back-scattered light that arise from temperature, vibration, and strain fluctuations, and changes caused by inherent fibre loss when using standard fibres (Miah and Potter 2017). Fibre optic sensors that measure ground vibration along the cable length must differentiate between noise and acoustic reflected waves and need improvements to detect minimal environmental changes. 
Nonlinear effects and dispersion profoundly affect the sensitivity and spatial resolution of fibre optics sensors, while dispersion also causes attenuation. Thus, we suggest that future research on fibre optic methods of prospecting focuses on developing new fibres with low loss and dispersion over the entire wavelength range of 1300-1650 nm. It is possible to detect various physical properties using fibre optical sensors in the laboratory, while only a few are field-tested and applied to geophysical problems. Therefore, efforts are required to change these fibre optical sensor techniques from the laboratory scale to the field scale with a reasonable sensing range, spatial resolution, and measurement sensitivity. The long-distance cable suffers from decreased mechanical strength as it is susceptible to breakage due to natural phenomena such as major earthquakes and fire (Lu et al. 2019a). The non-armoured fibre optic cables used as sensors are susceptible to physical damage, restoration problems, backup issues, and survivability problems and are more fragile than electrical wires. This new technology requires high installation and cable costs, expensive precision splicing, and specialised test equipment for different parameter measurements. Fibre losses and chromatic dispersion affect the bit rate via pulse broadening, limiting the system performance, and therefore present some disadvantages of fibre optic sensors for geophysical applications. Other challenges in applying the technology include fibre cable coupling with the ground, optical attenuation, and lack of broad-side sensitivity of the fibre cables.

\subsubsection{Fibre Cable Coupling}

Coupling between the fibre optics cable and the ground is a challenge in applying fibre optic sensors for geophysical surveys. In conventional land-based seismic surveys, geophones are either planted on the ground for surface seismic profiling (SSP) or mounted inside the borehole for VSP. However, the coupling between the cable and the medium remains a significant challenge for distributed fibre optic systems. Particularly for vibration measurements, an efficient transfer of source energy to the receiver is critical, requiring strong coupling between the cable and the medium (Munn et al. 2017). It is challenging to deploy the cables inside formations during vibration measurements in borehole environments and more challenging to clamp the fibre cables into the borehole wall like conventional geophones. Coupling is a significant factor in DAS VSP survey data quality, and several field experiments have proposed multiple coupling options. Cementing on the outside of the casing, clamping on the production casing, and inside the tubing (Correa et al. 2019; Li et al. 2015; Mateeva et al. 2014) are among field-tested coupling options (Fig. 16).

Cementing the fibre optic cable to the borehole wall provides the optimal coupling technique in terms of data quality ( $\mathrm{Li}$ et al. 2015) and presenting a similar SNR to geophone VSPs (Correa et al. 2017). Olofsson and Martinez (2017) used single-mode fibre optic cable cemented behind the casing and obtained a relatively low signal loss and minimal environmental noise through a 5.4-km-long fibre optic cable. Cementing to the wall and clamping to the production tubing may be suitable for deep boreholes. These coupling techniques have practical difficulties in shallow boreholes which may not have a well casing that extend beyond the top of the bedrock, or the production tubing may not be present at all. The field test experiment by Munn et al. (2017) proposed a coupling technique analogous to a fully cemented deployment in that the cable was continuously coupled directly to the formation with the use of a flexible borehole linearly inflated using hydrostatic pressure (Fig. 16). However, the coupling technique cannot be used for deep boreholes due to its depth limitations of up to $425 \mathrm{~m}$. 


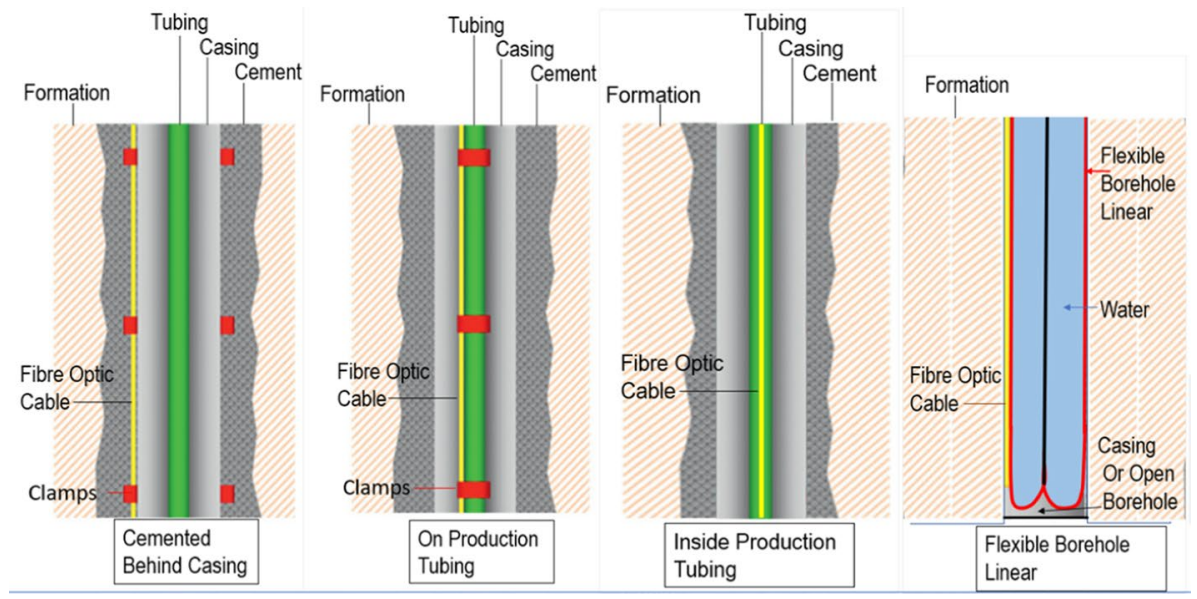

Fig. 16 Fibre optic cable coupling options in a borehole survey (modified from Munn et al. 2017; Naldrett et al. 2020)

The cost of installation and data quality, which are the main factors for choosing the type of coupling, can be selected based on the particular application and borehole details. Cementing the fibre cable outside of the casing is used to permanently monitor boreholes with the highest cost and data quality ( $\mathrm{Li}$ et al. 2015; Mateeva et al. 2014). It forms a better coupling with the formations resulting in higher SNR, though it is challenging to use in shallow boreholes. Deploying the cable on the production tubing is a semi-permanent deployment technique with lower cost and data quality (Correa et al. 2019; Li et al. 2015). Tubing installations usually present weak coupling, which leads to low DAS data quality. The on-tubing DAS VSP acquired demonstrates high noise levels relative to the signal (Correa et al. 2019). VSP data collected using fibre-optic cables deployed on production tubing suffer due to tube waves that travel along the fluid-solid boundary in boreholes (Hardage 1981). The inside tubing deployment can be done with low cost but higher noise data that requires more effort and processing before interpretation (Li et al. 2015).

Even though the tubing cable installation results in low data quality, it has been applied for several geophysical applications. It provides advantages for situations that cannot be done with cementing behind the casing. Daley et al. (2016) verified that fibres deployed on tubing could be used to acquire offset and walkaway VSP data. Mateeva et al. (2017) explained the possibility of using DAS on a tubing installation for 4D VSP. It has advantages to avoid the complexity of cementing a cable outside the long casing string, and the possibility of deploying the cable in pre-existing wells, where there is no opportunity to install a fibre behind the casing (Correa et al. 2019). The on tubing installation avoids interfering with perforation operations, and the cable can be retrieved and replaced if it is damaged. Moreover, there are field experiments to improve the coupling for DAS VSP data quality. Research in Louisiana suggested that the fibre installed in fluid-fill tubing would detect meaningful seismic signals (Mateeva et al. 2012). Schilke et al. (2016) and Constantinou et al. (2016) added extra slack to cables in wireline deployments to improve coupling. 


\subsubsection{Optical Attenuation}

Optical attenuation, which occurs due to various causes, affects the quality of data gathered using fibre optic sensors. It is difficult to extend the sensing range via fibre optic cables due to inherent attenuation along the fibre length, which is primarily dependent on the core diameter and the traveling light wavelength. Single-mode fibres are preferable for distributed sensing over long distances due to their lower attenuation than multi-mode fibres. The loss is a minimum $(0.2 \mathrm{~dB} / \mathrm{km})$ at $1550 \mathrm{~nm}$ in a single-mode fibre, and the intrinsic attenuation is higher in a multi-mode fibre than in a single-mode fibre of the same length (Miah and Potter 2017). Optical attenuation can be caused by hydrogen-induced loss, known as hydrogen darkening. In this situation, optical attenuation is caused by the diffusion of free hydrogen gas through fibre coatings into silica-based optical fibres, which produces light absorption in the infrared band. However, this phenomenon can be prevented by using hydrogen-resistant pure silica glass compositions and enhanced high-temperature coatings (Rehman and Mendez 2012).

\subsubsection{Lack of Broad-Side Sensitivity of the Cable}

The straight fibre optic cable is not sensitive to broad-side seismic waves or strain. When DAS functions, it senses the strain along the fibre axis, while the strain perpendicular to its axis can barely be recorded. DAS measurements using straight fibre optic cables sense the strain along the fibre axis due to p-waves rather than perpendicular to its axis due to s-waves (Li et al. 2015). The straight fibre may not record the dominant shear waves generated related to induced fractures during hydraulic fracturing with near offset DAS VSP and DAS microseismicity (Mateeva et al. 2014). p-waves that propagate nearly vertically during the near-surface seismic survey are poorly recorded using a horizontally deployed straight fibre compared to the VSP or slightly deviated well survey (Kuvshinov 2016). When the p-wave is incident on a straight fibre, where the cable and the fibre axis coincide, it will make an angle $\theta \leq 90^{\circ}$ (Fig. 17a). A field test by Mateeva et al. (2014) and a theoretical study by Kuvshinov (2016) have shown that DAS sensitivity to plane p-waves drops as

(a)

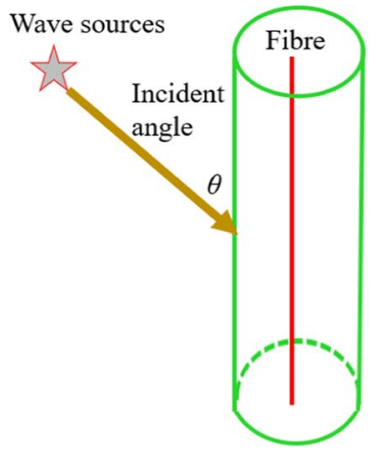

(b)

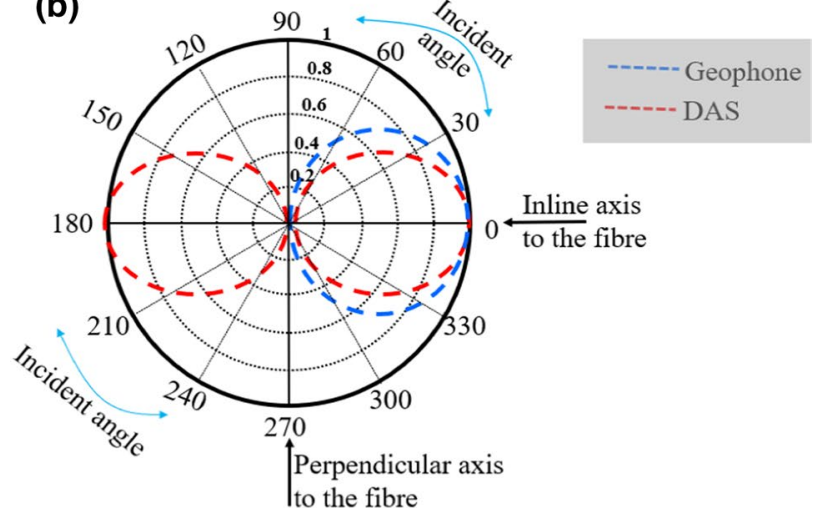

Fig. 17 Incident p-wave on the straight fibre (a) and approximate amplitude-incident angle plots of DAS and $1 \mathrm{C}$ conventional geophone (b) (modified from $\mathrm{Li}$ et al. 2015). The dashed line inside the circle refers to the normalized amplitude of the recorded p-wave 
$\cos ^{2} \theta$ with increasing incident angle $\theta$. The broadside seismic wave sensitivity of straight fibre during DAS measurement is more severe than the $1 \mathrm{C}$ conventional geophone ( $\mathrm{Li}$ et al. 2015). The broadside wave sensitivity drops $\sim \cos ^{2} \theta$ for DAS straight fibre and $\cos \theta$ for $1 \mathrm{C}$ conventional geophone. The p-wave amplitude variation with the incident angle for DAS and $1 \mathrm{C}$ geophone indicates that when $\theta=0$, the $\mathrm{p}$-wave travels parallel to the maximum axis amplitude. In contrast, as $\theta$ changes from zero, the amplitude decreases faster in DAS than the $1 \mathrm{C}$ conventional geophone (Fig. 17b).

To improve DAS cables' broad-side sensitivity, the concept of an HWC has been proposed and tested in the field (Fig. 18a). The response of HWC as a function of the incidence angle $\theta$ depends on the elastic properties of the cable and the ground and the wrapping angle $\alpha$ (Fig. 18b). Hornman et al. (2013) carried out the first field trial for the concept of broadside sensitivity of DAS systems and validated the WHC field data with 3C accelerometers. Later, Hornman (2017), Kuvshinov (2016), Lumens (2014) and Mateeva et al. (2014) reported theoretical and field-tested results of HWC for the DAS system. Mateeva et al. (2014) suggested that HWC could be a possible replacement for the lack of broad-side sensitivity of the straight fibre cables, while Kuvshinov (2016) gave conclusions regarding how HWC theoretically interacts with plane seismic waves in various conditions.

\subsection{Possibilities and Future Potential}

Despite the limitations that will hopefully be solved in the future, this new fibre optic sensor prospecting has great potential in geophysics. Techniques for measuring temperature, pressure, acoustic, and strain in distributed systems that detect single or multi-parameters are currently being developed. There are numerous opportunities to apply the developed sensors to improve multi-parameter, low-cost sensors with increased spatial resolution and reduced loss. The new prospects can measure dynamic and static responses via active/passive methods using fibre optical sensors (Jousset et al. 2018; Marra et al. 2018; Pevzner et al. 2017). Researches on the production of a better waveguide medium are increasing. Optical solitons, which are beats that can maintain their shape by balancing the negative impacts of scattering, are among those being investigated (Rajpoot et al. 2017). Photonics has been explored too, with photonic fibres applied as cladding to guide light through a hollow glass tube. Since the speed of light in air is faster than that in other materials, photonic-band-gap materials enable light to travel unconstrained through the air inside fibre

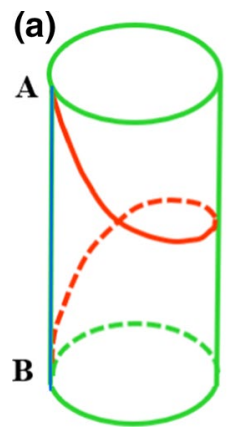

(b)

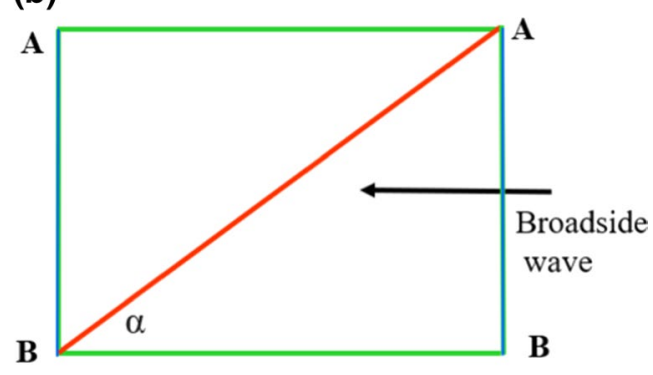

Fig. 18 Helically wrapped fibre for a broad-side sensitivity cable (a). The unwrapped cable surface forms a rectangle with the fibre laying on a diagonal (b). In both cases, red represents the fibre and green the cables, and $\alpha$ is a wrapping angle (modified from Mateeva et al. 2014) 
optic cables. The nearby glass's hollow core confines the light beam and creates a strictly forbidden region for light. Thus, the signals travel through the air rather than the glass (Ball 2001). There are possibilities to use microstructural, plasmatic, rare-earth element doped, and photonic fibre approaches in fibre optic sensor production, which will improve the sensing capacity.

The introduction of fifth-generation DWDM to fibre optic technology enables fibre optic cables to turn light at various wavelengths on and off during transmission of light along the fibre. This characteristic allows for fibre optic cables to be used in real-time active data recording that will be transferred through the Internet to aid decision-makers. As an example, real-time vibration detection will assist in early warning systems, potentially reducing injury and loss of life. Real-time data from the ocean floor using dark fibres help to predict earthquakes and reduce the corresponding tsunami risks. Fibre optic sensors will unquestionably be utilised in earth resource exploration, geohazard protection, and internal earth structural studies. Moreover, these sensors can detect the salinity of well fluid and the variability of viscosity, clogging merle, clay, salt, and silica in wells. This technology can be applied to detect the accumulation of silica, calcite, algae, and silt or fine materials in a well through screen openings for cased wells. Fibre optic methods are also expected to become a core tool for high-temperature geothermal wells in detecting mineral dissolution, changes in inflow from reservoir rocks to the well, and changes in borehole liquid density during drilling and production.

Fibre optic sensors will continue to attract geophysicists in the future. The development of computing and extensive data handling techniques will help one to interpret comprehensive data from long-distance fibre optic arrays. Among several big data handling techniques, artificial intelligence (Al) is a recent and helpful method to enhance the performance of future distributed fibre optic geophysical sensing systems through big data generation, artificial neural networks, and deep learning (Perol et al. 2018; Shiloh et al. 2018). Its applications for experimental studies in the laboratory and field, borehole geophysics, near-surface geophysics, and free-space dynamic big data exchange using satellites for earth investigation require improvement. The maximum sensitivity of fibre optic cables, the option to measure one or more physical parameters, the higher operating temperature, and the enhanced coatings for both protection and sensitivity (Rehman and Mendez 2012) are attractive for various near-surface and borehole geophysical surveys. Fibre optic prospecting methods, including point, distributed, passive, active, single-parameter, multi-parameter, or hybrid simultaneous multi-parameter detecting techniques, potentially represent a broad branch of geophysics. These approaches resemble the conventional electrical or electromagnetic methods of prospecting in terms of their diversity. However, further efforts are needed by scientists and researchers to promote these novel measurement techniques in the geophysical community, which may involve the introduction of these techniques as part of course curricula.

\section{Conclusion}

This work has endeavoured to refine the current technology limitations in fibre optic sensing systems so that the range of potential applications may be better understood, and research can focus on developing new technology. In this work, we have reviewed some of the widespread activity in optical fibre light scattering for sensing. We have introduced some of the underlying physics, conceptual ideas, and potential application areas to further 
geophysical study. Fibre optical methods of prospecting are a young discipline and not currently well embraced by academia. Therefore, we presented a comprehensive review of fibre optics geophysical sensors and research works based on Raman, Brillouin, and Rayleigh light back-scattering and FBG-based sensors for geophysical applications. The science and technology of fibre optics are progressing rapidly, but the potential for utilizing this technology for sensor applications in geophysics has mostly been untapped. Previous researches from the oil and gas industry have mainly focused on borehole geophysical survey environments. However, this technology has numerous other potential advantages for geophysical studies, including continuously measuring dynamic and static responses over time. Fibre optic sensing technology has the potential to detect several physical properties in laboratory settings such as temperature, pressure, strain, vibrations, light intensity, displacement, magnetic fields, electric fields, radiation levels, and fluid flow. However, only some of these parameters have been field-tested successfully for geophysical survey applications. Much of the current research in geophysics on fibre optical sensing technology aims to achieve DAS, DTS, DPS, and DSS with improved spatial resolution, sensing range, processing software, field layout, and instrumentation.

The technology allows high-sensitivity sensing, big data collection, and transmission of an enormous amount of information at the speed of light. Fibre optic sensors present a comprehensive set of modern geophysical methods integrated with the world's latest technology standard in real data transmission. It can use the computational techniques of artificial intelligence, machine learning, and deep learning to process big geophysical data. Different types of fibre structures and configurations can be utilised to tailor specific geophysical applications. A unique advantage is that the fibre optic sensing cable can be installed even under conditions where standard geophysical probes cannot be used. It can sense either single or multiple physical parameters simultaneously with superior spatial resolution and coverage compared to conventional geophysical techniques. It can be said that fibre optic technology is a revolutionary technological departure from traditional copper wires. The application of this technology in geophysics will result in a new paradigm. As we move forward in the Information Technology age, the movement of extreme amounts of data can potentially fall on the shoulders of this new technology. There is no doubt about the vast opportunities that fibre optic technology can give, and it should ideally be further researched and expanded to provide for future demands.

Despite these advantages, some limitations exist in sensor production, skilled workforces, survey procedures, and data processing techniques. Field tests and validation, where possible compared with standard geophysical methods, are required to use the recently developed fibre optic techniques for practical geophysical applications. The current high price of interrogation systems, the hydrogen darkening effect of the fibre cables, and their susceptibility to breakage from natural phenomena such as earthquakes and fires are among those limitations which can be potentially overcome in the future. The geophysical community will hopefully resolve these limitations as the benefits of this technology become more apparent and as these techniques become recognised as a component of optical fibre prospecting. Lastly, we want to emphasize that fibre optical prospecting can provide a comprehensive and modern research field in geophysics.

Funding Open access funding provided by University of Szeged.

Open Access This article is licensed under a Creative Commons Attribution 4.0 International License, which permits use, sharing, adaptation, distribution and reproduction in any medium or format, as long as you give appropriate credit to the original author(s) and the source, provide a link to the Creative Commons 
licence, and indicate if changes were made. The images or other third party material in this article are included in the article's Creative Commons licence, unless indicated otherwise in a credit line to the material. If material is not included in the article's Creative Commons licence and your intended use is not permitted by statutory regulation or exceeds the permitted use, you will need to obtain permission directly from the copyright holder. To view a copy of this licence, visit http://creativecommons.org/licenses/by/4.0/.

\section{References}

Ajo-franklin JB, Dou S, Lindsey NJ, Monga I, Tracy C, Robertson M et al (2019) Distributed acoustic sensing using dark fiber for near-surface characterization and broadband seismic event detection. Sci Rep 9(1328):1-14. https://doi.org/10.1038/s41598-018-36675-8

Alwis L, Sun T, Grattan KTV (2016) Developments in optical fibre sensors for industrial applications. Opt Laser Technol 78:62-66. https://doi.org/10.1016/j.optlastec.2015.09.004

Bakku S, Wills P, Fehler M (2014a) Monitoring hydraulic fracturing using distributed acoustic sensing in a treatment well. In: 84th SEG annual international meeting. Denver, USA, pp 5003-5008. https://doi. org/10.1190/segam2014-1559.1

Bakku S, Wills P, Fehler M, Mestayer J, Mateeva A, Lopez J (2014b) Vertical seismic profiling using distributed acoustic sensing in a hydrofrac treatment well. In: SEG Technical Program Expanded Abstracts, 5024-5028. https://doi.org/10.1190/segam2014-1559.1

Baldwin CS (2014) Brief history of fiber optic sensing in the oil field industry. In: Henry AW, Du H, Pickrell G, Udd E, Baldwin CS, Benterou JJ (eds) Proceedings of SPIE, vol 9098. Maryland, United States, pp 1-9. https://doi.org/10.1117/12.2050550

Ball P (2001) Novel "photonic-band-gap materials" promise to light up the pipes of the telecom network. Their breakthrough? They carry signals through air rather than glass. MIT Technology Review, 1-11. Retrieved from https://www.technologyreview.com/s/400981/the-next-generation-of-optical-fibers/. Accessed 16 Nov 2018

Bao X, Chen L (2011) Recent progress in Brillouin scattering based fiber sensors. Sensors 11(4):41524187. https://doi.org/10.3390/s110404152

Bao X, Chen L (2012) Recent progress in distributed fiber optic sensors. Sensors (Switzerland) 12(7):86018639. https://doi.org/10.3390/s120708601

Barberan C, Allanic C, Avila D, Billiot J, Hartog A, Frignet B, Lees G (2012) Multi-offset seismic acquisition using optical fiber behind tubing. In: 74th EAGE conference and exhibition. Copenhagen, Denmark

Barfoot D (2013) Efficient vertical seismic profiling using fiber-optic distributed acoustic sensing and realtime processing. In: EAGE Borehole Geophysics Workshop II. St. Julain's, Malta

Barrias A, Casas JR, Villalba S (2016) A review of distributed optical fiber sensors for civil engineering applications. Sensors. https://doi.org/10.3390/s16050748

Brown GA, Hartog A (2002) Optical fiber sensors in upstream oil and Gas. J Petrol Technol 54(11):63-65. https://doi.org/10.2118/79080-JPT

Castrellon-Uribe J (2012) Optical fiber sensors: an overview. In: Yasin M (ed) Fiber optic sensors. IntechOpen, Rijeka, pp 1-27. https://doi.org/10.5772/28529

Chabay I (1982) Optical waveguides. Photon plumbing for the chemistry lab: fiber optics, waveguides, and evanescent waves as tools for chemical analysis. Anal Chem 54(9):1071A-1080A. https://doi. org/10.1021/ac00246a004

Chen R, Yan A, Wang Q, Chen KP (2014) Fiber-optic flow sensors for high-temperature environment operation up to $800^{\circ} \mathrm{C}$. Opt Lett 39(13):3966-3969. https://doi.org/10.1364/OL.39.003966

Constantinou A, Farahani A, Cuny T, Hartog AH (2016) Improving DAS acquisition by real-time monitoring of wireline cable coupling. In: 86th SEG annual meeting. Dallas, USA, Expanded Abstracts, pp 5603-5607. https://doi.org/10.1190/segam2016-13950092.1

Correa J, Egorov A, Tertyshnikov K, Bona A, Pevz-Ner R, Dean T et al (2017) Analysis of signal to noise and directivity characteristics of DAS VSP at near and far offsets-a CO2CRC Otway Project data example. Lead Edge 36:9941-9947. https://doi.org/10.1190/tle36120994a1.1

Correa J, Pevzner R, Bona A, Tertyshnikov K, Freifeld B, Robertson M, Daley T (2019) 3D vertical seismic profile acquired with distributed acoustic sensing on tubing installation: a case study from the CO2CRC Otway Project. Interpretation, SEG Special Section. https://doi.org/10.1190/ INT-2018-0086.1 
Daley TM, Freifeld BM, Ajo-Franklin J, Dou S, Pevzner R, Shulakova V et al (2013) Field testing of fiberoptic distributed acoustic sensing (DAS) for subsurface seismic monitoring. Leading Edge 32(6):699_ 706. https://doi.org/10.1190/tle32060699.1

Daley TM, Miller DE, Dodds K, Cook P, Freifeld BM (2016) Field testing of modular borehole monitoring with simultaneous distributed acoustic sensing and geophone vertical seismic profiles at Citronelle, Alabama. Geophys Prospect 64(5):1318-1334. https://doi.org/10.1111/1365-2478.12324

Danardatu H, Gregersen S, Altern E, Pellegrini I (2014) Data acquisition and processing of carbon rod conveyed DTS and DAS in very long horizontal wells: first trial in North Sea Danish Sector. In: SPE annual technical conference and exhibition, Amsterdam, The Netherlands

Dean T, Cuny T, Hartog A (2015) Determination of the optimum gauge length for borehole seismic surveys acquired using distributed vibration sensing. In 77th EAGE conference \& exhibition, expanded abstracts. Madrid, Spain. https://doi.org/10.3997/2214-4609.201412740

Dean T, Cuny T, Hartog A (2016) The effect of gauge length on axially incident p-waves measured using fibre optic distributed vibration sensing. Geophys Prospect 65:184-193. https://doi. org/10.1111/1365-2478.12419

Domingues MF, Rodriguez C, Martins J, Tavares C, Marques C, Alberto N et al (2018) Cost-effective optical fiber pressure sensor based on intrinsic Fabry-Perot interferometric micro-cavities. Opt Fiber Technol 42(February):56-62. https://doi.org/10.1016/j.yofte.2018.02.016

Dong Y, Zhang H, Chen L, Bao X (2012) $2 \mathrm{~cm}$ spatial-resolution and $2 \mathrm{~km}$ range Brillouin optical fiber sensor using a transient differential pulse pair. Appl Opt 51(9):1229-1235. https://doi.org/10.1364/ ao.51.001229

Elprocus (2019) Introduction to fiber optic sensors and their types with applications. https://www.elpro cus.com/diffrent-types-of-fiber-optic-sensors/

Farhadiroushan M, Parker T, Shatalin S (2016) Method and apparatus for optical sensing. WO Patent App. PCT/GB2016/050625.

Ferdinand P (2014) The evolution of optical fiber sensors technologies during the 35 last years and their applications in structure health monitoring. In: 7th European workshop on structural health monitoring. Nantes, France

Fernández-Ruiz M, Soto M, Williams E, Martin-Lopez S, Zhan Z, Gonzalez-Herraez M, Martins H (2020) Distributed acoustic sensing for seismic activity monitoring. APL Photon 5(030901):1-16. https://doi.org/10.1063/1.5139602

Fidanboylu K, Efendioglu H (2009) Fiber optic sensors and their applications. In: 5th International Advanced Technologies Symposium (IATS'09), Karabuk, Turkey, pp 1-6. https://doi. org/10.2514/6.2004-2131

Frings J, Walk T (2011) Distributed fiber optic sensing enhances pipeline safety and security. Oil Gas Eur Mag 3:2-4

Froggatt M, Moore J (1998) High-spatial-resolution distributed strain measurement in optical fiber with Rayleigh scatter. Appl Opt 37(10):1735-1740. https://doi.org/10.1364/AO.37.001735

Ghahfarokhi P, Carr T, Song L, Shukla P, Pankaji P (2018) Seismic attributes application for the distributed acoustic sensing data for the marcellus shale: new insights to cross-stage flow communication. In: SPE hydraulic fracturing technology conference and exhibition. Texas, pp 1-20. https:// doi.org/10.2118/189888-MS

Hansen H, Bakkevig M, Kluth R (2009) ZipLog — the third method for well intervention: practical field experience and unique opportunities for the future. In: SPE offshore Europe oil and gas conference and exhibition. Aberdeen, UK, pp 1-5

Hardage B (1981) An examination of tube wave noise in vertical seismic. Geophysics 46:892-903. https ://doi.org/10.1190/1.1441228

Harris K (2017) The use of distributed acoustic sensing for 4D monitoring using vertical seismic profiles: results from the aquistore $\mathrm{CO} 2$ storage project. Carleton University Ottawa, Ontario. Retrieved from https://curve.carleton.ca/b00ef536-8930-47c6-87ce-f2a9b858739f

Hartog A (2017) In: Mendez A (ed) An introduction to distributed optical fibre sensors. Taylor \& Francis Group

Hecht J (1999) City of light: the story of fiber optics. Oxford University Press, Oxford . https://doi. org/10.1353/tech.2002.0013

Hecht J (2002) Understanding fiber optics, 4th edn. Prentice Hall, London

Henninges J, Zimmermann G, Büttner G, Schrötter J, Erbas K, Huenges E (2005) Wireline distributed temperature measurements and permanent installations behind casing . In: Proceedings world geothermal congress. Antalya, Turkey, pp 1-5 
Hill K, Fujii Y, Johnson D, Kawasaki B, Hill K, Fujii Y et al (1978) Photosensitivity in optical fiber waveguides: application to reflection filter fabrication. Appl Phys Lett 32(10):647-649. https://doi. org/10.1063/1.89881

Hornman J (2017) Field trial of seismic recording using distributed acoustic sensing with broadside sensitive fibre-optic cables. Geophys Prospect 65:35-46. https://doi.org/10.1111/1365-2478.12358

Hornman K, Kuvshinov B, Zwartjes P, Franzen A (2013) Field trial of a broadside-sensitive distributed acoustic sensing cable for surface seismic. In: 75th EAGE conference and exhibition, pp 1-2. London, UK. Extended Abstracts: European Association of Geoscientists \& Engineers. https://doi. org/10.3997/2214-4609.20130383

Hurtig E, Grobwig S, Kuhn K (1997) Distributed fibre optic temperature sensing: a new tool for longterm and short-term temperature monitoring in boreholes. Energy Sources 19(1):1495-1498. https ://doi.org/10.1080/00908319708908832

Jackson J (2009) Classical electrodynamics, 3rd edn. Wiley, New York

Jenny R (2000) Fundamentals of fiber optics. An introduction for beginners. New York

Jones D (1998) Introduction to fiber optics. Navy electricity and electronics training series. NAVEDTRA

Jousset P, Reinsch T, Ryberg T, Blanck H, Clarke A, Aghayev R et al (2018) Dynamic strain determination using fibre-optic cables allows imaging of seismological and structural features. Nat Commun. https:// doi.org/10.1038/s41467-018-04860-y

Jreij S, Trainor-Guitton W, Simmons J (2018) Improving point-sensor image resolution with distributed acoustic sensing at Brady's enhanced geothermal system. In: 43rd workshop on geothermal reservoir engineering, Stanford University, pp 1-12

Karrenbach M, Cole S, Ridge A, Boone K, Kahn D, Rich J et al (2019) Fiber-optic distributed acoustic sensing of microseismicity, strain and temperature during hydraulic fracturing. Geophysics 84(1):D11D23. https://doi.org/10.1190/geo2017-0396.1

Kuvshinov B (2016) Interaction of helically wound fibre-optic cables with plane seismic waves. Geophys Prospect 64:671-688. https://doi.org/10.1111/1365-2478.12303

Li M, Wang H, Tao G (2015) Current and future applications of distributed acoustic sensing as a new reservoir geophysics tool. Open Petrol Eng J 8(1):272-281. https://doi.org/10.2174/187483412015062 $5 \mathrm{E} 008$

Li Z, Zhan Z (2018) Pushing the limit of earthquake detection with distributed acoustic sensing and template matching: a case study at the Brady geothermal field. Geophys J Int 215:1583-1593. https://doi. org/10.1093/gji/ggy359

Lindsey N, Martin E, Dreger D, Freifeld B, Cole S, James S et al (2017) Fiber-optic network observations of earthquake wavefields. Geophys Res Lett 44(23):11792-11799. https://doi.org/10.1002/2017GL0757 22

Liu X, Jin B, Bai Q, Wang Y, Wang D, Wang Y (2016) Distributed fiber-optic sensors for vibration detection. Sensors 16:1-31. https://doi.org/10.3390/s16081164

López-Higuera J (1998) Optical sensors. Universidad de Cantabria, Cantabria

Lu P, Lalam N, Badar M, Liu B, Chorpening BT, Buric MP, Ohodnicki PR (2019a) Distributed optical fiber sensing: review and perspective. Appl Phys Rev 6(4):1-35. https://doi.org/10.1063/1.5113955

Lu X, Thomas P, Hellevang J (2019b) A review of methods for fibre-optic distributed chemical sensing. Sensors 19(2876):2-20. https://doi.org/10.3390/s19132876

Lumens P (2014) Fibre-optic sensing for application in oil and gas wells. Eindhoven University of Technology, Eindhoven University of Technology, Eindhoven. https://doi.org/10.6100/IR769555

Mahajan V (2014) Fundamentals of geometrical optics. Society of Photo-Optical Instrumentation Engineers, Washington

Marra G, Clivati C, Luckett R, Tampellini A, Kronjäger J, Wright L et al (2018) Ultrastable laser interferometry for earthquake detection with terrestrial and submarine cables. Science 361(6401):486-490. https://doi.org/10.1126/science.aat4458

Martins H, Martin-Lopez S, Corredera P, Salgado P, Frazão O, González-Herráez M (2013) Modulation instability-induced fading in phase-sensitive optical time-domain reflectometry. Opt Lett 38(6):872874. https://doi.org/10.1364/OL.38.000872

Masoudi A, Belal M, Newson T (2013) A distributed optical fibre dynamic strain sensor based on phaseOTDR. Meas Sci Technol. https://doi.org/10.1088/0957-0233/24/8/085204

Mateeva A, Mestayer J, Cox B, Kiyashchenko D, Wills P, Lopez J (2012) Advances in Distributed Acoustic Sensing (DAS) for VSP. In: 82nd SEG annual international meeting, expanded abstracts. Las Vegas, USA

Mateeva A, Lopez J, Chalenski D, Tatanova M, Zwartjes P, Yang Z et al (2017) 4D DAS VSP as a tool for frequent seismic monitoring in deep water. Lead Edge 36:995-1000. https://doi.org/10.1190/tle36 120995.1 
Mateeva A, Lopez J, Potters H (2014) Distributed acoustic sensing for reservoir monitoring with vertical seismic profiling. Geophys Prospect 62:679-692

Mcdaniel A (2017) District-scale ground heat exchange performance with fiber optic distributed temperature sensing. University of Wisconsin-Madison, Wisconsin

Media P (2019) Fiber optics: understanding the basics. Fiber Optics \& Communications. Retrieved from https://www.photonics.com/Article.aspx?AID=25151. Cited Dec 2019

Mestayer J, Cox B, Wills P, Kiyashchenko D, Lopez J, Costello M (2011) Field trials of distributed acoustic sensing for geophysical monitoring. In: 81st SEG annual international meeting, expanded abstract. San Antonio, USA. Society of Exploration Geophysicists, pp 4253-4257. https://doi. org/10.1190/1.3628095

Mestayer J, Grandi S, Cox B, Wills P, Mateeva A, Lopez J (2012) Distributed acoustic sensing for geophysical monitoring. In: 74th EAGE conference and exhibition. Copenhagen, Denmark.

Miah K, Potter D (2017) A review of hybrid fiber-optic distributed simultaneous vibration and temperature sensing technology and its geophysical applications. Sensors (Switzerland) 17(11):1-25. https://doi. org/10.3390/s17112511

Michie C (2000) Optical fiber sensors for advanced composite materials. In: Comprehensive composite materials. Elsevier Science Ltd, pp 475-491. https://doi.org/10.1016/B0-08-042993-9/00154-6

Molenaar M (2013) Field cases of hydraulic fracture stimulation diagnostics using fiber optic distributed acoustic sensing (DAS) measurements and Analyses. In: SPE Middle East unconventional gas conference and exhibition. Muscat, Oman

Momota M, Hasan M (2018) Hollow-core silver coated photonic crystal fiber plasmonic sensor. Opt Mater 76:287-294. https://doi.org/10.1016/j.optmat.2017.12.049

Motil A, Bergman A, Tur M (2016) [INVITED] State of the art of Brillouin fiber-optic distributed sensing. Opt Laser Technol 78:81-103. https://doi.org/10.1016/j.optlastec.2015.09.013

Muanenda Y (2018) Recent advances in distributed acoustic sensing based on phase-sensitive optical time domain reflectometry. J Sens 3897873:1-16. https://doi.org/10.1155/2018/3897873

Muanenda Y, Oton C, Faralli S, Nannipieri T, Signorini A, Pasquale F (2016) Hybrid distributed acoustic and temperature sensor using a commercial off-the-shelf DFB laser and direct detection. Opt Lett 41(3):587-590. https://doi.org/10.1364/OL.41.000587

Munn J, Coleman T, Parker B, Mondanos M, Chalari A (2017) Novel cable coupling technique for improved shallow distributed acoustic sensor VSPs. J Appl Geophys 138:72-79. https://doi. org/10.1016/j.jappgeo.2017.01.007

Naldrett G, Parker T, Shatalin S, Mondanos M, Farhadiroushan M (2020) High-resolution Carina distributed acoustic fibre-optic sensor for permanent reservoir monitoring and extending the reach into subsea fields. SEG Spec Topic Reservoir Monit 38:71-76. https://doi.org/10.3997/1365-2397. fb2020012

Nesladek N (2017) Comparing distributed acoustic sensing to three-component geophones in an underground mine. Montana Tech. https://digitalcommons.mtech.edu/grad_rsch

Ning I, Sava P (2018) Multicomponent distributed acoustic sensing: concept and theory. Geophysics 83(2):1-8. https://doi.org/10.1190/geo2017-0327.1

Olofsson B, Martinez A (2017) Validation of DAS data integrity against standard geophones-DAS field test at aquistore site. Special Section: Fiber-Optic Distributed Sensing. The Leading Edge. SEG (December), pp 981-986. https://doi.org/10.1190/tle36120981.1

Otani T, Goto K, Abe H, Tanaka M, Yamamoto H, Wakabayashi H (1995) 5.3 Gbit/s $11300 \mathrm{~km}$ data transmission using actual submarine cables and repeaters. Electron Lett 31(5):380-381

Park J, Bolognini G, Lee D, Kim P, Cho P, Pasquale F, Park N (2006) Raman-based distributed temperature sensor with simplex coding and link optimization. Photon Technol Lett 18(17):1879-1881. https://doi.org/10.1109/1pt.2006.881239

Parker L, Thurber C, Zeng X, Li P, Lord N, Fratta D et al (2018) Active-source seismic tomography at the brady geothermal field, nevada, with dense nodal and fiber-optic seismic arrays. Seismol Res Lett 89(5):1629-1640. https://doi.org/10.1785/0220180085

Parker T, Shatalin SV, Farhadiroushan M, Miller D (2013) Distributed acoustic sensing: recent field data and performance validation. In: 2nd EAGE workshop on permanent reservoir monitoring-current and future trends, extended abstracts. Stavanger, Norway

Patterson J, Cardiff M, Coleman T, Wang H, Feigl K, Akerley J, Spielman P (2018) Geothermal reservoir characterization using distributed temperature sensing at Brady Geothermal Field, Nevada. In: 43rd Geothermal reservoir engineering workshop, vol 36. Stanford University Stanford, California, pp 1024a1-1024a7. https://doi.org/10.1190/tle36121024a1.1 
Paulsson B, Wylie M, Thornburg J, He R, Hardiman H, Patel D (2019) A fiber optic single well seismic system for geothermal reservoir imaging and monitoring. In: 44th workshop on geothermal reservoir engineering. Stanford University, Stanford, California, USA, pp 1-8

Peng F, Wu H, Jia X, Rao Y, Wang Z, Peng Z (2014) Ultra long high sensitivity $\phi$-OTDR for high spatial resolution intrusion detection of pipelines. Opt Express 22(11):138104-213810. https://doi. org/10.1364/OE.22.013804

Perol T, Gharbi M, Denolle M (2018) Convolutional neural network for earthquake detection and location. Sci Adv 4(2):1-24. https://doi.org/10.1126/sciadv.1700578

Pevzner R, Urosevic M, Popik D, Shulakova V, Glubokovskikh S, Ziramov S et al (2017) 4D surface seismic tracks small supercritical $\mathrm{CO}_{2}$ injection into the subsurface : $\mathrm{CO}_{2} \mathrm{CRC}$ Otway Project. Int J Greenhouse Gas Control 63(March):150-157. https://doi.org/10.1016/j.ijggc.2017.05.008

Qin Z, Chen L, Bao X (2012) Wavelet denoising method for improving detection performance of distributed vibration sensor. IEEE Photonics Technol Letter 24(7):542-544. https://doi.org/10.1109/ LPT.2011.2182643

Rajpoot S, Singh P, Solanki S, Yasin SJ (2017) Future trends in fiber optics communication. Int J Cybern Inform IJCI 6(1/2):23-28. https://doi.org/10.5121/ijci.2017.6203

Rastogi V (2018) Fiber optics lecture notes. Department of Physics Indian Institute of Technology, Roorkee, NPTEL., (September), 2018. Retrieved September, 2018, https://www.nptel.ac.in/cours es/115107095/4

Read T, Bense V, Hochreutener R, Bour O, Le Borgne T, Lavenant N, Selker J (2015) Thermal-plume fibre optic tracking (T-POT) test for flow velocity measurement in groundwater boreholes. Geosci Instrum Methods Data Syst 4(2):197-202. https://doi.org/10.5194/gi-4-197-2015

Read T, Bour O, Selker J, Bense V, Borgne T, Hochreutener R, Lavenant N (2014) Active-Distributed Temperature Sensing to continuously quantify vertical flow in boreholes. Water Resour Res 50:3706-3713. https://doi.org/10.1002/2014WR015273

Rehman S, Mendez A (2012) Optical fibers present opportunities and challenges for geophysical applications. Offshore Mag 72(3):1-5. https://doi.org/10.1021/ja012023z

Reinsch T, Henninges J, Götz J, Jousset P, Bruhn D, Lüth S (2015) Distributed acoustic sensing technology for seismic exploration in magmatic geothermal areas. In: World geothermal congress 2015. Melbourne, Australia, pp 1-5

Ren M (2016) Distributed optical fiber vibration sensor based on phase- sensitive optical time domain reflectometry. University of Ottawa, Ottawa

Research, \& Markets (2017) Distributed Fiber Optic Sensor/Sensing (DFOS) Market Analysis, 2014-2025

Schilke S, Donno D, Chauris H, Hartog A, Farahani A, Pico Y (2016) Numerical evaluation of sensor coupling of distributed acoustic sensing systems in vertical seismic profiling. In: 86th SEG annual meeting, Dallas. Dallas, USA, Expanded Abstracts, pp 677-681

Shah R, Agrawal Y (2011) Introduction to fiber optics: Sensors for biomedical applications. Indian J Pharm Sci 73(1):17-22. https://doi.org/10.4103/0250-474X.89752

Shiloh L, Eyal A, Giryes R (2018) Deep learning approach for processing fiber optic DAS seismic data. OSA Publishing. https://doi.org/10.1364/OFS.2018.ThE22

Sidek O, Afzal H (2011) A review paper on fiber-optic sensors and application of PDMS materials for enhanced performance. In: Symposium on business, engineering and industrial applications (ISBEIA). Langkawi, Malaysia: IEEE, pp 458-463. https://doi.org/10.1109/ISBEIA.2011.60888 58

Silkina T (2014) Application of distributed acoustic sensing to flow regime classification. Norwegina University of Sciences and Technology, Trondheim

Siska P, Latal J, Bujok P, Vanderka A, Klempa M, Koudelka P et al (2016) Optical fiber based distributed temperature systems deployment for measurement of boreholes temperature profiles in the rock massif. Opt Quant Electron 48(2):1-21. https://doi.org/10.1007/s11082-016-0379-3

Skoog D, Holler F, Crouch S (2007) Principles of Instrumental Analysis (6th edition). Thomson Brooks/ Cole

Smolen J, Spek A (2003) Distributed Temperature Sensing. A DTS primer for oil and gas production. Tech., Shell

Tanner M, Dyer S, Baek B, Hadfield R, Nam S (2011) High-resolution single-mode fiber-optic distributed Raman sensor for absolute temperature measurement using superconducting nanowire single-photon detectors) High-resolution single-mode fiber-optic distributed Raman sensor for absolute temperature measu. Appl Phys Lett 201110(2011):1-3. https://doi.org/10.1063/1.3656702

Tech E (2018) Fiber optic lines could soon deliver earthquake detection too. https://www.digitaltrends. com/cool-tech/fiber-optic-lines-detect-earthquake/ 
Tosi D, Schena E, Molardi C, Korganbayev S (2018) Fiber optic sensors for sub-centimeter spatially resolved measurements: review and biomedical applications. Opt Fiber Technol 43:6-19. https:// doi.org/10.1016/j.yofte.2018.03.007

Udd E (2006) Fiber optic sensors: an introduction for engineers and scientists. Wiley, Hoboken

Udd E, Spillman WB (2011) Fiber optic sensors: an introduction for engineers and scientists. Wiley, Hoboken

Webster P, Cox B, Molenaar M (2014) Distributed acoustic sensing for cross-well frac monitoring introduction: integrated hydraulic fracture stimulation diagnostics. GeoConvention 1-8

Xue Z, Shi J, Yamauchi Y, Durucan S (2018) Fiber optic sensing for geomechanical monitoring: (1) -distributed strain measurements of two sandstones under hydrostatic confining and pore pressure conditions. Appl Sci 8(2103):1-18. https://doi.org/10.3390/app8112103

Yahei K, Mustumi I, Kenya K, Kazuo H (2009) Fiber-optic distributed strain and temperature sensing with very high measurand resolution over long range using coherent OTDR. J Lightwave Technol 27(9):1142-1146

Yang K, Xu T, Ma L, Li F (2019) Theoretical study of optimal gauge length in a helically wound cable for distributed acoustic sensing system. In: Proceedings of SPIE 11340, AOPC 2019: optical fiber sensors and communication, vol 11340. Beijing, China, pp 1-7. https://doi.org/10.1117/12.2547716

Yang Y, Wang D, Xu B, Wang Z (2018) Optical fiber tip interferometer gas pressure sensor based on anti-resonant reflecting guidance mechanism. Opt Fiber Technol 42(February):11-17. https://doi. org/10.1016/j.yofte.2018.02.013

Yuksel K, Wuilpart M, Moeyaert V, Megret P (2009) Optical frequency domain reflectometry: a review. In: 11th international conference on transparent optical networks. Ponta Delgada,a, Island of São Miguel, Azores, Portugal

Zerlux (2019) Laser tools . Retrieved from http://www.zerlux.com

Zhang J, Zhu T, Zhou H, Huang S, Liu M, Huang W (2016) High spatial resolution distributed fiber system for multi-parameter sensing based on modulated pulses. Opt Express 24(24):27482-27493. https:// doi.org/10.1364/OE.24.027481

Zhang Y, Jung Y, Freifeld B, Finsterle S (2018) Using distributed temperature sensing to detect CO2leakage along the injection well casing. Int J Greenhouse Gas Control 74:9-18. https://doi.org/10.1016/j.ijggc .2018.04.011

Zhang Y, Su H, Ma K, Zhu F, Guo Y, Jiang W (2018) Optic-fiber temperature sensor. In: Temperature Sensing. IntechOpen, pp 5-21. https://doi.org/10.5772/intechopen.74207

Publisher's Note Springer Nature remains neutral with regard to jurisdictional claims in published maps and institutional affiliations. 